\title{
Los movimientos vecinales en Parque Alcosa (Sevilla). Claves para avanzar de una cultura de resistencia hacia la construcción de alternativas para la mejora del hábitat
}

\author{
Neighbourhood movements in Parque Alcosa (Seville). Keys for \\ moving from a culture of resistance towards the construction of \\ alternatives for habitat improvement
}

\author{
Marta Donadei ${ }^{1}$ \\ Fecha de recepción: 01-02-2021 - Fecha de aceptación: 20-05-2021 \\ Hábitat y Sociedad (ISSN 2173-125X), n. . 14, noviembre de 2021, pp. 71-96. \\ https://doi.org/10.12795/HabitatySociedad.2021.i14.05
}

\section{Summary}

Parque Alcosa, in Seville, is a neighbourhood that is well known mainly for the marked identity of its inhabitants and for the important tradition of mobilizations aimed at overcoming the difficulties created by its peripheral position and its deprivations, which have been present since the origin of the neighbourhood.

Through the application of some methodological tools developed in the framework of the Social Production and Management of Habitat (PSGH) from a qualitative approach, this article aims to deepen, from a complex perspective, in the transformation phenomena that have affected the neighborhood of Parque Alcosa in order to demonstrate the transformative potential of CIVITAS in the processes of transformation of the Habitat.

\section{Key words}

Participation; Ctitizen Empowerment; Social Production and Management of Habitat; Neighbourhood; Seville; Parque Alcosa

\section{Resumen}

Parque Alcosa, en Sevilla, es un barrio muy reconocido principalmente por la marcada identidad de sus habitantes y por la importante tradición de movilizaciones orientadas a superar las dificultades creadas por su posición periférica y sus carencias, presentes ya desde el origen del barrio.

A través la aplicación de algunas herramientas metodológicas desarrolladas en el marco de la Producción y Gestión Social del Hábitat (PSGH) desde un enfoque cualitativo, con este artículo se quiere profundizar, desde una perspectiva compleja, en los fenómenos de trasformación que han afectado al barrio de Parque Alcosa con el fin de evidenciar el potencial transformador de la CIVITAS en los procesos de transformación del Hábitat.

\section{Palabras clave}

Participación; Empoderamiento ciudadano; Producción y Gestión Social del Hábitat; Barrio, Sevilla; Parque Alcosa

1 Doctora en Arquitectura. Investigadora del grupo ADICI (HUM-810) y Asistente Honoraria del Departamento de Urbanística y Ordenación del Territorio de la ETSAS (Universidad de Sevilla, España). E-mail: donadei.marta@gmail.com. ORCID: https://orcid. org/0000-0003-1620-1459. 
AGRADECIMIENTOS: La autora quiere agradecer a todos las vecinas y vecinos del barrio que han accedido a ser entrevistados, por su participación desinteresada, por su confianza en prestarme muchos documentos, fotografías, recortes de prensa, libros y recuerdos, y por el tiempo que me han dedicado (incluso en varias sesiones) para ayudarme a entender las dinámicas sociales de su barrio a través de sus vivencias.
2 Esta es una de las opiniones más recurrentes expresadas por las personas entrevistadas a lo largo de los últimos años de investigación cualitativa, orientada al estudio de procesos de participación activados desde las administraciones.

\section{Introducción}

Desde hace varias décadas, a nivel internacional se debate sobre la importancia de la participación como elemento clave para el alcance de los objetivos de sostenibilidad ambiental y de justicia social. Tal presupuesto se basa sobre dos cuestiones fundamentales: por una parte, colectivos y personas que constituyen la ciudadanía son sujetos activos en el uso y trasformación del Hábitat en cuanto definen la territorialidad a través de sus prácticas cotidianas (Bonora, 2006a; Donadei, 2019b); por otra, las ciudades son y tienen que ser espacios de construcción colectiva e inclusión (Lefebvre, 1968) y por ello es necesario construir "marcos de participación y concertación entre actores que permitan democratizar los procesos de trasformación y gestión territoriales en sus distintas escalas" (de Manuel Jerez y López Medina, 2017, p. 23), reconociendo la diversidad de personas y colectivos involucrados.

Efectivamente, conceptos como participación ciudadana y sostenibilidad son ahora en gran parte usados en el discurso político e incluso técnico, sobre todo en relación a ciertas políticas públicas (y en particular modo las de carácter local) (cfr. Sánchez-Rubio García, 2009, p. 7), pero los significados que se les atribuyen están acompañados de una confusión que parece ser el resultado de la intención, sobre todo por parte del sistema económico, de no precisar su contenido ni el modo de llevarlo a la práctica (Naredo, 2010); así, estos conceptos se han quedado a menudo vacíos, convirtiéndose frecuentemente en prácticas de "simple captación de consenso o mistificación populista" (Bonora 2006b, p. 115). Incluso cuando haya real voluntad política, la participación se convierte a menudo en una práctica de carácter consultivo a posteriori, en el que la percepción de los participantes es que "ya las decisiones han sido tomadas a priori y solo buscan vendernos el proyecto". ${ }^{2}$

$\mathrm{Al}$ contrario, es preciso invertir los procesos dando protagonismo a los de abajo-arriba que rescaten al ciudadano de la condición de consumidor/usuario y le devuelvan su papel de protagonista, de ciudadano de la poliV en la construcción cultural y colectiva de la ciudad, invirtiendo "por completo el sistema actual de toma de decisiones [...]. En aras de este objetivo, el de generar procesos de planificación verdaderamente democrática, hay que reinventar el urbanismo para convertirlo realmente en un lenguaje de uso común al servicio de todos los ciudadanos" (Verdaguer Viana-Cárdenas, 2002a, pp. 16-17).

\section{La relación URBS-CIVITAS-POLIS según la Producción y Gestión Social del Hábitat}

El planteamiento de esta investigación encuentra sus bases teóricas y metodológicas en el marco conceptual de la Producción y Gestión Social del Hábitat (PGSH), entendiendo por Trasformación Social del Hábitat el conjunto de procesos tendientes a la transformación del hábitat existente y activados desde la participación de los distintos actores que conforman la sociedad (Figura 1).

En este sentido la Producción Social del Hábitat define el Hábitat Social como interacción de situaciones físicas, económicas, ambientales, simbólicas, jurídicas y políticas, "interrelacionadas, interactuantes y coactuantes", no reducibles a una mera agregación de piezas (Pelli, 2010, p. 41), y que por ello necesita una visión compleja y transdisciplinaria 
(Morin, 2004): "cualquier acto de producción, eliminación o conservación de una parte o componente del hábitat modifica el equilibrio, el funcionamiento y la calidad de todo el conjunto y afecta los de otros componentes, existentes o futuros" (Pelli, 2010, p. 41).

Según señala de Manuel Jerez (2010), tales dimensiones identificadas por Pelli (2006) pueden ser agrupadas en las tres dimensiones que propone Capel $(2003,2011)$ y en la que se encuentran "las raíces etimológicas de la ciudad: la URBS, la CIVITAS y la POLIS" (de Manuel Jerez, 2010, p. 16): la dimensión física (el soporte físico del barrio, ciudad o ámbito territorial considerado), la dimensión social y la dimensión organizativa, relacionada esta última con las esferas política y administrativa. Las relaciones existentes entre estas tres dimensiones implican que cualquier cambio en una de ellas tiene consecuencias en las otras dos; de igual manera, si se quiere intervenir en el hábitat social se puede empezar partiendo de un cambio en cualquiera de las tres dimensiones, elegidas estratégicamente, para inducir cambios sobre las otras dos (Cfr. de Manuel Jerez, 2010, pp. 15-17).

Pero la Polis, que en el contexto actual está tecnocratizada y totalmente alejada de la ciudadanía, es una dimensión que necesita una renovación para alejarse de las actuales dinámicas que se generan alrededor de las políticas urbanas y territoriales, y que a menudo ven primar los intereses económicos particulares de algunas categorías de actores. Para ello es necesaria una toma de conciencia por parte de la ciudadanía sobre la importancia de su implicación real para retomar el equilibrio de la URBS (de Manuel Jerez, 2010): "tenemos que hacer de la construcción de la POLIS (los mecanismos de decisión ciudadana) el eje sobre el que descanse la construcción de la URBS (la formalización física de la ciudad) y para ello es preciso transformar la CIVITAS (el entramado social y cultural)" (de Manuel Jerez, 2006, p. 89).

Efectivamente, hasta hace escasamente tres siglos la construcción de la ciudad era un proceso fundamentalmente colectivo: "al tratarse de un proceso lento, la construcción de la ciudad no precisaba de expertos, se trataba de un fenómeno colectivo en el que participaban de diverso modo todos los habitantes" (Verdaguer Viana-Cárdenas, 2002b, p. 175). Para Sassen (2011) esto tiene relación con el concepto de incompletitud (incompleteness) de las ciudades: una ciudad viva es por definición una ciudad incompleta, no cristalizada, y este factor es esencial para permitirle evolucionar adaptándose constantemente a las nuevas necesidades de la sociedad cambiante: siempre existen resquicios que permiten este cambio y esto es lo que ha permitido a las grandes ciudades del pasado poder resistir el cambio y seguir existiendo hasta el día de hoy. En definitiva, lo que ha sucedido en las ciudades a lo largo de los siglos es un proceso de ajuste permanente entre realidad física y realidad socio-económica, por el intento de adecuar el tejido urbano existente a las pautas de organización espacial de las diversas formaciones sociales y económicas (Troitiño Vinuesa, 1991): lo que ha variado a lo largo de la historia es la escala de las intervenciones y la intencionalidad que hay por detrás. Pero su constante transformación no depende solamente de las grandes decisiones que proceden desde arriba (desde los diferentes niveles administrativos), sino también de la suma de múltiples pequeñas acciones que surgen desde abajo, desde los ciudadanos que, más o menos organizados, se apropian de los lugares y los van cambiando poco a poco (Sassen, 2011), a través de la lucha, la protesta o sencillamente cambiando la forma de ocupar los espacios y actuar en ellos. Así, frente al urbanismo convencional planificado, en

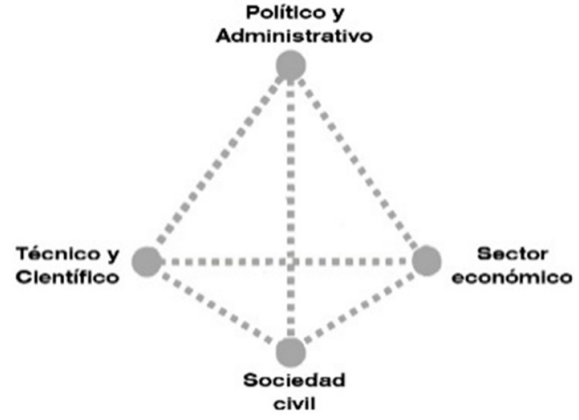

Figura 1: Principales grupos de actores del Hábitat. Fuente: de Manuel Jerez y Donadei, 20181.

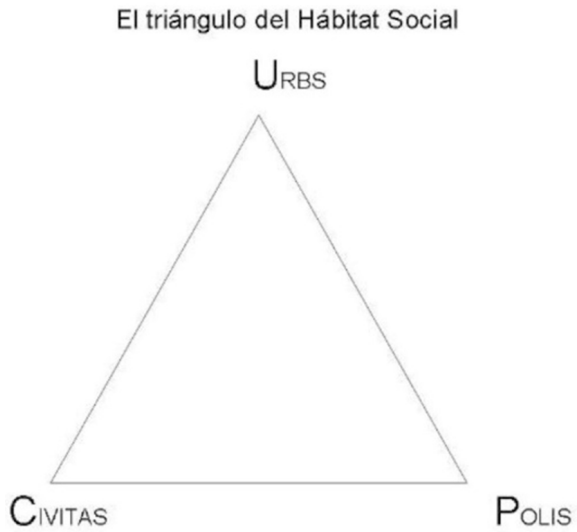

Figura 2: El triángulo del Hábitat Social. Fuente: de Manuel Jerez, 2010. 
donde los procesos, dirigidos y controlados, acaban convirtiéndose en una ratificación de decisiones políticas previas, la ciudad emergente, aunque tienda a pasar desapercibida frente al modelo urbano planificado (Freire, 2009), puede dar lugar a círculos virtuosos en la transformación del hábitat, espirales que empiezan desde los márgenes antes de convertirse eventualmente en mayoritarios e institucionalizarse.

\section{Objeto de la investigación, metodología y fuentes}

Parque Alcosa es un barrio vulnerable de Sevilla, caracterizado por ser periférico, por presentar grandes carencias desde sus comienzos y elementos de obsolescencia física en sus edificios, y por tener una larga trayectoria de iniciativas socio-comunitarias orientadas a la mejora de su hábitat. Desde sus origines, a finales de la década de los 60, el aislamiento y las carencias presentes en Parque Alcosa han ido influyendo en las dinámicas sociales del barrio, generando una importante experiencia de movilización social que ha tenido el objetivo de superar las dificultades creadas por su condición al margen del planeamiento.

Así, este caso de estudio se ofrece como singular e idóneo para evidenciar el potencial transformador de la CIVITAS en los procesos de transformación del Hábitat, a través de la aplicación de las herramientas metodológicas propuestas por de Manuel Jerez (2010) (Figuras 1 y 2) y que nos ayudan en una mejor comprensión de los fenómenos que afectan al hábitat desde una perspectiva compleja.

De una forma más específica, con respecto a las dinámicas de transformación que ha subido el barrio de Parque Alcosa desde sus comienzos hasta hoy, se llegará a demostrar lo siguiente:

- Por una parte, en la dimensión física (consecuencia a su vez de decisiones de carácter político-administrativo) se encuentra el principal factor de activación de la movilización social y la cohesión entre sus habitantes y su marcada identidad. La configuración del tejido social y su evolución a lo largo de los años ha terminado influyendo en la configuración urbana del barrio, cristalizando ciertas formas de relacionarse y de usar el espacio urbano. En Alcosa los movimientos sociales hicieron ciudad ahí donde dominaban las carencias típicas de un NO-barrio.

- Por otro lado, y en conexión con lo anterior, la historia de movilizaciones y luchas vecinales de Alcosa, junto a sus logros, demuestran como la CIVITAS tiene (o puede tener) capacidad transformadora de la URBS, más allá de la presencia o menos de unos mecanismos y canales de decisión democráticos propicios (POLIS).

Por otro lado, se incidirá sobre la importancia de involucrar a los otros grupos de actores (ciudadanía) que intervienen en el Hábitat Social para poder activar cambios, dando espacio a las potencialidades de las comunidades locales, pero al mismo tiempo canalizándolas hacia soluciones integrales y estratégicas.

Para realizar el estudio de caso tal como se ha planteado, se ha recurrido a la aplicación de una metodología con enfoque prevalentemente cualitativo. Aunque en el acercamiento al caso de estudio había un interés investigativo general, fue necesario entregarse a un diseño metodológico de tipo emergente (Erlandson, et al., 1993; Valles, 1999; Patton, 2002) en el que los rasgos específicos del enfoque de investiga- 
ción se han ido definiendo paulatinamente a medida que se profundizaba en el trabajo de campo. Es por ello por lo que, por ejemplo, en un primer momento no estaba previsto un acercamiento al caso de estudio desde una perspectiva de género; pero a lo largo de las entrevistas y del trabajo de campo ha ido emergiendo la importancia del papel de las mujeres en las luchas vecinales y por ello se ha decidido dedicar un apartado específico a su protagonismo en algunas reivindicaciones, principalmente relacionadas con las carencias presentes en el barrio con respecto a las tareas de cuidado.

El trabajo de investigación se ha estructurado esencialmente en dos partes.

La primera ha sido de acercamiento inicial al barrio a través de un estudio de carácter principalmente documental (sobre todo desde el ámbito urbanístico) y por medio de la observación cualitativa en las diferentes visitas al barrio.

Así surgieron las primeras pistas necesarias para orientar la segunda fase, en la cual la principal herramienta de investigación fue la entrevista en profundidad de tipo semiestructurado. Tal elección estuvo orientada a obtener una comprensión profunda de las dinámicas estudiadas dando voz a las diferentes posiciones y perspectivas de los informantes considerados clave para profundizar en los temas de la investigación, puesto que es de esperar que cada entrevistado o entrevistada tenga una experiencia única respecto a un mismo acontecimiento. Aunque se disponía de un guion de preguntas no fue respetado en todo momento, ya que su función no era otra que la de ayudar a no olvidar cuestiones y temas concretos considerados importantes para los objetivos de la investigación. Así, el hilo conductor de la conversación en muchos casos se fue construyendo en función del entrevistado, obligando a abandonar la estructura inicial pensada para darle más fluidez a su discurso. Además, las entrevistas se complementaron con otras técnicas necesarias para identificar hitos y reconstruir relatos en la historia de luchas vecinales a través de analizadores históricos (Red CIMAS, 2015)..$^{3}$

Se han realizado un conjunto de 16 entrevistas a 12 personas consideradas como informantes clave del barrio (e identificados esencialmente a través de la técnica denominada "bola de nieve") (Tabla 1). Así, una vez finalizada la fase de realización de las entrevistas se ha procedido a convertir estas conversaciones en textos para posteriormente poder codificarlos y analizarlos. Por todo lo dicho anteriormente, se ha optado por un tipo de transcripción verbatim que, según Deslauriers (2004), consiste en transcribir toda la entrevista de manera íntegra, reflejando el lenguaje verbal, no verbal y contextual de los datos; las transcripciones se realizaron siguiendo las recomendaciones indicadas por muchos autores de literatura específica (Tabla 2). Asumiendo la postura por la cual los motivos de la conducta social solo pueden ser entendidos por la explicación que hacen los propios actores sobre dichos motivos, los textos procedentes de estas entrevistas aparecerán en verbatim.

En paralelo a las entrevistas se generó un archivo considerable de documentos de diferente naturaleza, ${ }^{4}$ facilitados esencialmente por los y las entrevistadas (o sus contactos cercanos) que ayudaron a profundizar en el estudio de los diferentes hitos y a contrastar la información recogida. Del mismo modo se consultaron las hemerotecas online de los principales medios de comunicación local (principalmente $A B C S e-$ villa, Diario de Sevilla y EuropaPress) desde 1969 hasta la actualidad.
3 La metodología aplicada en este caso de estudio ha sido detallada en el monográfico 125 de los Cuadernos de Investigación Urbanística de la ETSAM (Donadei, 2019a).

4 Registros oficiales y documentos públicos (como artículos de prensa, estudios teóricos, etc.) y registros producidos por los propios informantes o colectivos en los que están involucrados, de carácter individual y grupal, privados o con finalidad pública (páginas webs, actas, libros, fotos, mails privados, etc.). 


\begin{tabular}{|c|c|c|}
\hline Código & Perfil/es & Tipo \\
\hline PALC01 & $\begin{array}{l}\text { Hombre, de mediana edad. No es vecino del barrio, pero está íntimamente ligado con este desde } \\
\text { los años } 80 \text { al pertenecer al equipo docente cel Centro de Personas Adultas, alrededor del cual se } \\
\text { han ido dinamizando númeras luchas reivindicativa sobre todo a partir de la década de los } 90 .\end{array}$ & $\begin{array}{l}\text { semiestructurada } \\
2 \text { sesiones }\end{array}$ \\
\hline PALC02 & $\begin{array}{l}\text { Hombre mayor, pensionista y vecino de Alcosa. Sevillano, llega al barrio en } 1982 \text { y a partir de } 1984 \\
\text { entra en el Centro de Personas Adultas, donde también colabora activamente hasta la década de } \\
\text { los } 90 \text { (además de ser componente de la Asociación Alumnos/as "la Amistad" CE Personas adultas, } \\
\text { o, como lo llaman las personas que frecuentan el Centro, el APA). Es entre los componentes más } \\
\text { activos de la FEA. }\end{array}$ & semiestructurada \\
\hline PALC03 & $\begin{array}{l}\text { Hombre de } 45 \text { años, miembro de la Asociación para la Rehabilitación Integral de Alcosa y de la } \\
\text { Coordinadora Ciudadana la FEA. Su implicación en el barrio es reciente, a partir de 2007, cuan- } \\
\text { do lo eligen como presidente de la Comunidad en el bloque donde vive su madre. Pero es solo a } \\
\text { partir de } 2012 \text { que entra activamente dentro de las asociaciones ya mencionadas. Actualmente está } \\
\text { más desconectado por diferentes razones. }\end{array}$ & semiestructurada \\
\hline PALC04 & $\begin{array}{l}\text { N. es una mujer de } 62 \text { años mientras que T. tiene } 10 \text { años más. Ambas entraron en el barrio entre } \\
\text { finales de los } 70 \text { y principios de los } 80 \text {, jóvenes, casadas y con hijos muy pequeños. Ambas han sido } \\
\text { alumnas del Centro de Adultos desde sus comienzos, colaborando activamente en algunas activida- } \\
\text { des desarrolladas en el centro; además pertenecen a la APA (Asociación "la Amistad" CE Personas } \\
\text { adultas), al grupo de mujeres NOSOTRAS y al Teatro Social de las mujeres. }\end{array}$ & semiestructurada \\
\hline PALC05 & $\begin{array}{l}\text { Hombre de } 58 \text { años, vecino del barrio desde sus comienzos y propietario de una de las actividades } \\
\text { comerciales más conocidas e históricas del barrio. En los } 90 \text { fue uno de los principales fundadores } \\
\text { de la (ya desaparecida) Asociación de Comerciantes y Empresarios del Parque Alcosa (ACEPAL); } \\
\text { en aquellos mismos años fue además uno de los principales financiadores del Boletín "Habla tu } \\
\text { Barrio", realizado por el taller de prensa del Centro de Personas Adultas. }\end{array}$ & semiestructurada \\
\hline PALC06 & $\begin{array}{l}\text { V. y L. son dos vecinos del barrio pertenecientes a la Asociación de Vecinos Antonio Machado, la } \\
\text { asociación histórica del barrio que jugó un papel crucial en la canalización de todo el movimiento } \\
\text { ciudadano de Alcosa en las décadas de los } 70 \text { y 80; actualmente la asociación tiene su representa- } \\
\text { ción en la Junta Municipal del Distrito Este. V. fue una pieza clave de la asociación sobre todo en } \\
\text { las primeras décadas, ocupando un papel más institucional a partir de 1985. L. partenece a una ge- } \\
\text { neración posterior y desde hace unos diez años es quien ha tomado el relevo. }\end{array}$ & $\begin{array}{l}\text { grupal } \\
\text { semiestructurada }\end{array}$ \\
\hline PALC07 & $\begin{array}{l}\text { Mujer de unos } 70 \text { años, vecina de Alcosa. Entró en el barrio a finales de los } 70 \text { con casi } 30 \text { años y } \\
\text { ya casada; en sus primeros años en Alcosa fue soda de la AVV Antonio Machado. Es alumna del } \\
\text { Centro de Personas Adultas desde 1986, donde entró para sacar el graduado, y pertenece a la APA } \\
\text { (Asociación "la Amistad" CE Personas adultas), al grupo de mujeres NOSOTRAS y al Teatro Social } \\
\text { de las mujeres. }\end{array}$ & semiestructurada \\
\hline PALC08 & $\begin{array}{l}\text { Mujer de } 75 \text { años, vecina de Alcosa. Hoy jubilada, en su juventud trabajó en una fábrica textil, pero } \\
\text { dejó el trabajo al quedarse embarazada de su primera hija. Entró en el barrio en 1973, ya casada, em- } \\
\text { barazada y con dos hijas. Fue alumna del centro a partir de } 1988 \text { y pertenece a la APA (Asociación "la } \\
\text { Amistad" CE Personas adultas), al grupo de mujeres NOSOTRAS y al Teatro Social de las mujeres. }\end{array}$ & semiestructurada \\
\hline PALC11 & $\begin{array}{l}\text { Hombre de unos } 40 \text { años, llegó al barrio de niño, en 1981. Su mayor activismo dentro del barrio } \\
\text { (sobre todo con la Movida Pro Parque) se produjo entre } 1996 \text { y } 2014 \text {, aunque en los últimos años } \\
\text { su involucración fue cada vez más intermitente al tener que pasar largas estancias en el extranjero } \\
\text { por cuestiones de estudio y trabajo. }\end{array}$ & semiestructurada \\
\hline PALC12 & $\begin{array}{l}\text { Hombre mayor, viudo, vecino de Alcosa y pensionista. Nacido fuera de Andalucía, llegó al barrio } \\
\text { en } 1992 \text { ya adulto y con su familia formada. Es un vecino activo del barrio, implicado desde } 2008 \\
\text { en la lucha por la rehabilitación integral de Alcosa. Pertenece a la Asociación para la Rehabilita- } \\
\text { ción Integral de Alcosa y es presidente de su Intercomunidad (no se espicifica aquí el nombre de } \\
\text { la Intercomunidad para garantizar su anonimato). }\end{array}$ & $\begin{array}{l}1 \text { semi- estructurada } \\
3 \text { informales }\end{array}$ \\
\hline OTROS02 & $\begin{array}{l}\text { Mujer mayor, vecina de Alcosa. Es una valiosa informante clave para entender mejor la situación } \\
\text { del barrio en su época más antigua (boicot al supermercado y lucha para la plaza de abastos). } \\
\text { Alumna histórica del Centro de Personas Adultas (en el que participó desde sus comienzos) y per- } \\
\text { tenece al Teatro Social de las mujeres de Alcosa, en donde es considerada un poco como la tita de } \\
\text { todos los hijos de sus otras compañeras. }\end{array}$ & informal \\
\hline OTROS06 & $\begin{array}{l}\text { Hombre mayor y vecino activo de Alcosa, implicado en la lucha para la rehabilitación integral de } \\
\text { Alcosa. Pertenece a la Asociación para la Rehabilitación Integral de Alcosa, además de ser presi- } \\
\text { dente de su Intercomunidad (no se especifica aquí el nombre de la Intercomunidad para garanti- } \\
\text { zar su anonimato). }\end{array}$ & informal \\
\hline
\end{tabular}

NOTA: se ha optado por mantener oculto el nombre de los informantes dado que, al tratarse de vednos de un mismo barrio, la falta de cautela en esta investigación podría afectar a las relaciones cotidianas desarrolladas dentro de la comunidad. 
Los movimientos vecinales en Parque Alcosa (Sevilla). Claves para avanzar de una cultura de resistencia...

\begin{tabular}{|c|c|}
\hline CLAVES & LO QUE INDICAN \\
\hline A & Se emplean letras mayúsculas para identificar los hablantes \\
\hline$(\mathrm{x})$ & material intelegible \\
\hline$()$. & Pausa \\
\hline$[\ldots]$ & Pausa más larga \\
\hline JAMÁS & $\begin{array}{l}\text { palabras en mayúscula para indicar que se ha pronunciado en voz má alta que } \\
\text { anteriores y posteriores }\end{array}$ \\
\hline jamás & $\begin{array}{l}\text { palabra en minúscula subrayada indica que ha sido pronunciada en voz más } \\
\text { baja que las anteiores y posteriores }\end{array}$ \\
\hline- & ruptura abrupta en la cadena sintagmática \\
\hline Pero nosotros no quere- & $\begin{array}{l}\text { ruptura abrupta en la cadena sintagmática acompañado por corte en la últi- } \\
\text { ma palabra }\end{array}$ \\
\hline $\begin{array}{l}\text { lo empezamos a ver cuando [es ver- } \\
\text { dad] fuimos }\end{array}$ & cuando se solapan intervenciones \\
\hline bbbb & $\begin{array}{l}\text { cuando resulta imposible saber que se está diciendo porque varias personas } \\
\text { hablan }\end{array}$ \\
\hline ++es asít+ & las palabras entre signos + se pronuncian con un ascenso de voz \\
\hline -entre nosotros- & las palabras entre signos - se pronuncian con un descenso de voz \\
\hline$\{$ representantes $\}$ & transcripción incierta \\
\hline $\begin{array}{l}<\text { ríe }>,<\text { con el dedo indica la parro- } \\
\text { quia }>\end{array}$ & descripción de expresiones no verbales \\
\hline La demogracia (sic) & $\begin{array}{l}\text { indica que no es error de transcripción: es la palabra tal y como se ha pronun- } \\
\text { ciado }\end{array}$ \\
\hline $\begin{array}{l}\text { y dicen 'Oye, vamos a hacer un pro- } \\
\text { yecto chachi' }\end{array}$ & cuando el hablante está reconstruyendo lo dicho por tercera persona \\
\hline $\begin{array}{l}\text { - podemos decir que el barrio es au- } \\
\text { tosuficiente- }\end{array}$ & $\begin{array}{l}\text { cuando el hablante intercala un dato o un texto en el que aporte información } \\
\text { adicional, sin resultar estrictamente necesaria }\end{array}$ \\
\hline , & pausa entre oraciones \\
\hline . & final de una oración \\
\hline$?$ & interrogación \\
\hline$!$ & exclamación \\
\hline
\end{tabular}

\section{Acercamiento al barrio: efectos del binomio POLIS- URBS sobre la CIVITAS}

El barrio de Parque Alcosa se encuentra en una posición de borde urbano, ubicado en una llanura de terreno arcilloso al nordeste del núcleo urbano de Sevilla, junto a la Autovía A-4. Aunque hasta el día de hoy esta posición de borde ha constituido un elemento de debilidad muy grande, tiene un carácter estratégico fundamental de cara a la activación de nuevas políticas urbanas orientadas a la recuperación del equilibrio en la relación ciudad-campo-territorio.

El barrio tiene una superficie de 93,14 Ha, que sumada a la del Parque del Tamarguillo (96 Ha) y el Polígono industrial de la Algodone$\mathrm{ra}^{5}(12,54 \mathrm{Ha})$ comprenden en total 201,68 Ha. Tanto el parque como el polígono tienen una especial vinculación con el barrio: la Algodonera ha sido lugar de trabajo para muchos de sus habitantes y hoy, aun-
Tabla 2: Reglas básicas utilizadas para las transcripciones. Fuente: adaptación propia a partir de las indicaciones de Montañés Serrano, 2010. 
Figura 3: Contexto previo a la construcción del barrio. Fuente: elaboración propia a partir de la Ortofotografía digital pancromática del vuelo americano, 1956-1957 (disponible en ide.SEVILLA).

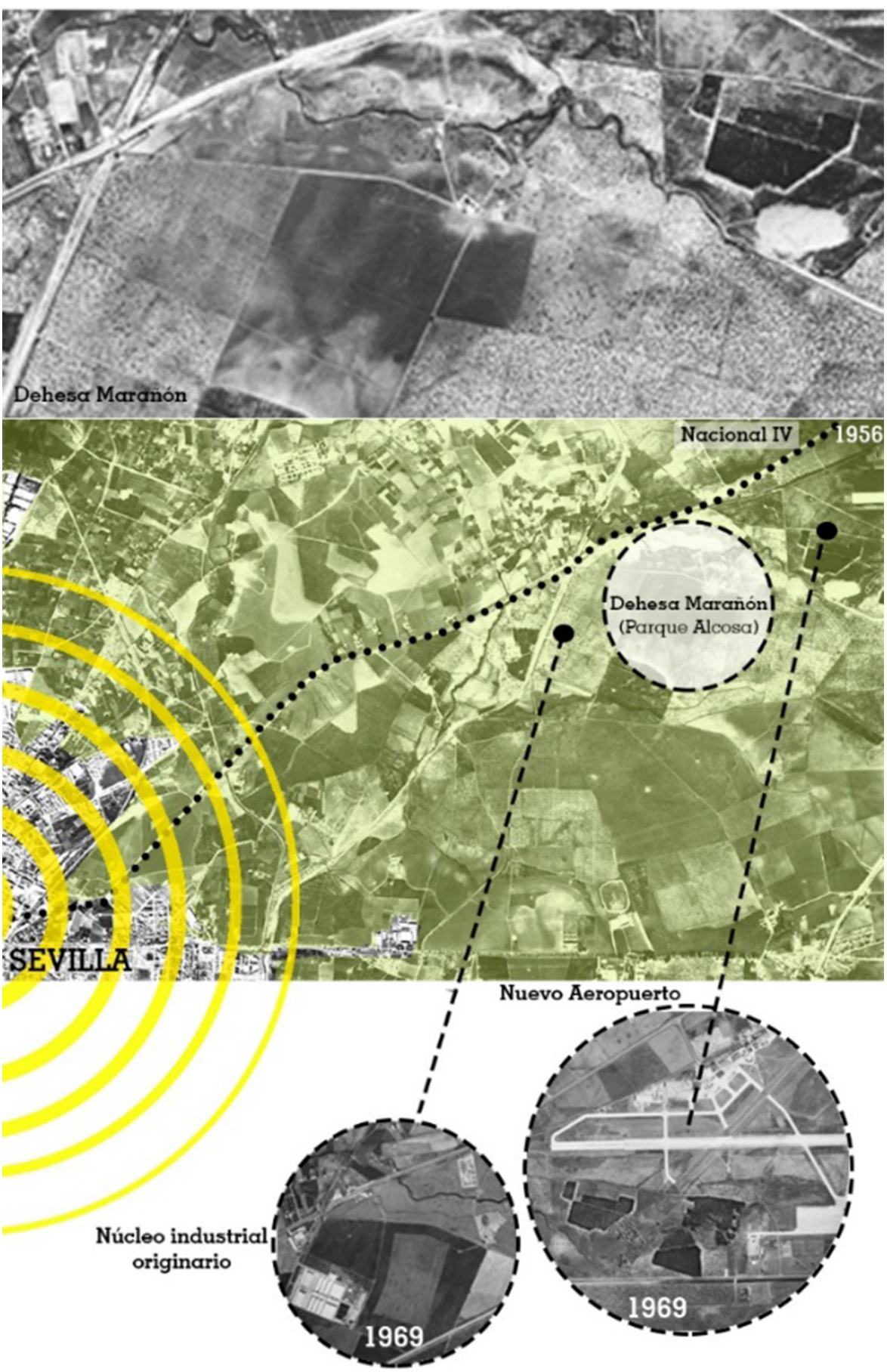

que inutilizada, constituye un área de oportunidad para la reactivación económica y social del barrio; el parque (espacio natural de gran diversidad biológica y que tiene un rango ciudad) es el producto de una intensa reivindicación vecinal surgida en defensa de un espacio reconocido 'históricamente' por las vecinas y vecinos como su lugar de esparcimiento y de encuentro.

Se trata de un barrio relativamente reciente. Como era habitual en el urbanismo de los años setenta, el barrio nace al amparo de la especulación urbanística producida con los últimos Planes de Desarrollo (en particular, con el "Segundo Plan de Desarrollo Económico y Social", relativo a los años 1968-71) y a conclusión de una década (los sesenta) caracterizada por un fuerte desarrollismo y un gran crecimiento económico en toda España: la cada vez mayor mecanización de las labores agrícolas, combinada con el alto atractivo del modelo de vida urbano y de los sa- 
larios más elevados de la industria, generaron unos movimientos migratorios de tipo masivo en toda España (éxodo rural) hacia las principales capitales industriales españolas (Barcelona, Madrid, Valencia, Bilbao, etc.). En esta época Sevilla experimenta un gran desarrollo industrial que traerá consigo la necesidad de producir casas baratas y funcionales para albergar a la nueva clase obrera recién llegada desde las áreas rurales: Parque Alcosa, junto a Polígono Norte y gran parte del Polígono de San Pablo y del Polígono Sur, forman el grupo de cuatro grandes polígonos residenciales que culminan el proceso de empuje constructivo y expansión residencial que caracterizó toda la década de los 60 en Sevilla. En este contexto, sobre todo en las barriadas periféricas y polígonos que se fueron generando, el aislamiento (físico o social), junto a la necesidad de empleo y vivienda, fueron activando a menudo "prácticas de apoyo mutuo y resistencia" (Contrera Becerra, 2019, p. 305). Todo ello, junto al activismo militante tanto de la Iglesia de base como de partidos políticos clandestinos, constituyeron el "caldo de cultivo de las primeras experiencias de autorganización vecinal durante el franquismo, que posteriormente aprovecharían fórmulas asociativas como las asociaciones de cabezas de familia y las asociaciones de vecinos [que en Sevilla se legalizaron entre 1976-78] con la que tratar de solucionar los problemas de las mencionadas barriadas" (Ibíd.)

Parque Alcosa surge como promoción privada de viviendas de protección oficial ${ }^{6}$ vinculada al polígono industrial de la antigua Algodonera ${ }^{7}$ alejada del casco urbano y al margen del planeamiento. Se conectaba a la ciudad por medio de la antigua carretera Nacional IV (hoy autovía del Sur, A-4), y el vacío intermedio entre el barrio y el núcleo urbano consolidado estaba constituido por suelos rústicos (Figura 3).

El barrio toma el nombre del acrónimo de la empresa inmobiliaria creada en la década de los setenta por el constructor valenciano Alfredo Corral Cervera (AL.CO.S.A., Alfredo Corral Sociedad Anónima) y se construyó sobre una parte de lo que era antes una antigua dehesa perteneciente a la familia Gregorio Marañón. El comienzo de la construcción se remonta al año 1969, pero no es hasta 1971 cuando se inaugura oficialmente (Figura 4).

Su lejanía del centro y su no previsión en los planes urbanísticos de la época motivó que los primeros años de vida del barrio estuviesen caracterizados por la falta de equipamientos e infraestructuras básicas de abastecimiento y saneamiento. Calles sin terminar, bloques de viviendas en estructura, acerados en malas condiciones, alumbrado público insuficiente... ${ }^{8} \mathrm{El}$ agua potable se distribuía por medio de camiones cisterna y no había escuelas, ni guarderías, ni centro de salud, ni plaza de abastos. Todo esto propició unas malas condiciones de habitabilidad en lo que acabó siendo una ciudad dormitorio, en un contexto en el cual dominaba una sensación de obra permanente.

El desarrollo de la ciudad de Sevilla a lo largo de las décadas siguientes no ha ayudado a la integración del barrio (Figura 5). Su expansión hacia el Este, con el refuerzo del sistema de carreteras y la colmatación de los terrenos entre el centro consolidado y Alcosa ha mostrado la falta de una intención integradora: al crecer, la ciudad no se une con el barrio, sino que lo mantiene aislado, rodeándolo de vías de circulación rodada de gran envergadura e infraestructuras que funcionan como barrera. La configuración de las conexiones de los ejes articuladores del barrio con las principales arterias externas dificulta la entrada y salida de los coches en el barrio, interrumpiendo además la continuidad de los recorridos peatonales y ciclistas.
6 Esta y otras actuaciones urbanísticas contemporáneas con el mismo carácter especulativo se estaban desarrollando en Sevilla al amparo del II Plan Nacional de la Vivienda (1961-1976), cuyos fondos presupuestarios estaban destinados en gran medida a los promotores privados (Díaz Hernández y Parreño Castellano, 2006). Más allá de los objetivos sociales, estas políticas de ayuda pública a la promoción privada protegida reflejan la importancia del papel asignado y desempeñado por la actividad inmobiliaria para la consecución de los objetivos de crecimiento y desarrollo económico del país (prestando especial atención a los objetivos cuantitativos) (Díaz Hernández y Parreño Castellano, 2006; González Ordovás, 2013) y que encuentra sus orígenes el Primer Plan de Vivienda de 1944-1954, cuyas medidas de fomento estaban orientadas a la construcción más que a la demanda, para "reducir la tasa de desempleo e impulsar la actividad económica" (Pérez Barrasa, Rodriguez Coma y Blanco Moreno 20102, p. 12).

7 Actualmente denominado núcleo industrial "Virgen de los Reyes", hoy inactivo.

8 En diferentes coloquios informales mantenidos con algunos informantes salió a la luz el hecho de que existen diferentes zonas del barrio en donde las farolas y focos presentes han sido instalados por la propia comunidad. 
Figura 4: Inauguración del barrio. Fuente: Foto de archivo de la Federación de Entidades de Alcosa (FEA)

Figura 5: Situación en el contexto de la ciudad. Fuente: Alumnas de la asignatura del Taller 4- Barrio" (ETSA Sevilla, Curso $2014 / 151$
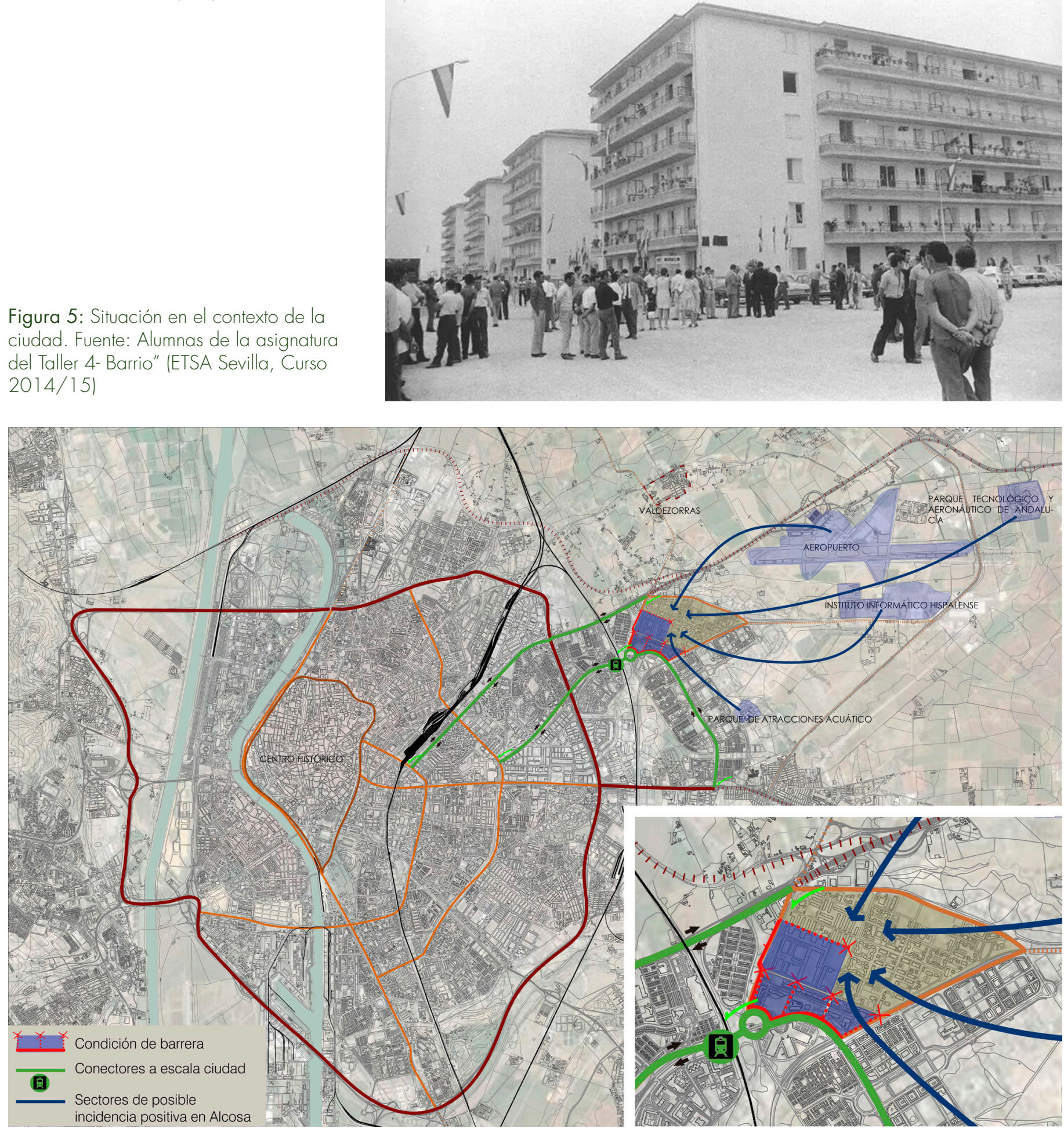

9 Estas expresiones han sido pronunciadas por algunos vecinos a lo largo del trabajo de campo; al mismo tiempo, se nota en muchas otras frases, como "ipero aquí también es Sevilla!” (PALC12).

10 Se trata de una broma recurrente, pronunciada por personas diferentes (de otros barrios de Sevilla) y que no se conocen entre sí al escucharme decir "voy a Parque Alcosa”.
Parque Alcosa está "más allá de la SE-30", es "otra ciudad"; ${ }^{9}$ para quien no es de aquí, Alcosa es el barrio que "está al sur de Córdoba”. ${ }^{10}$ Esta condición incluso emerge en algunas anécdotas vividas por las vecinas y vecinos y, ya sean ciertas o susceptibles de exageraciones (voluntarias o involuntarias), no dejan de ser significativas para entender lo radicada que dicha percepción está en el imaginario del barrio (Figura 6).

Pero fue precisamente esta condición físico-espacial de isla la que hizo que Alcosa se convirtiera en uno de los barrios con más tradición de movilización vecinal: las dificultades sufridas para conseguir incluso 


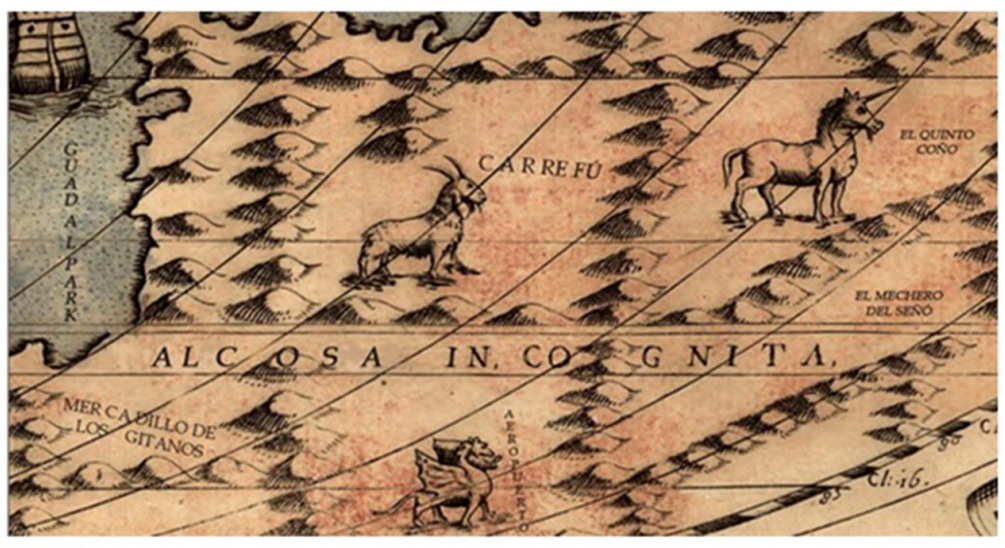

Defaparecioo un abenturero que bujaba una nueva ruta al \$arque 2lleoja

Grupos de búsqueda con helicópteros del tulipán y perros salchicha ron brandi Soberano al cupllo rastrean la insaluable disfancia entre el Dolígono San Dablo y la "terra incógnifa" del Darque Elrosa, pn busra del auenturero Crisfobal C. El pxplorador de Eansas Cify (auenida de), se halla desaparerido desde el pasado jueves, ruando iniciaba una arriesgada trauesía en busca de una rufa a pie al remofo barrio seuillano. Esa misión de búsqueda, Ianzada esta misma mañana desôe Querto eprico, aun no ha hallado rastro alguno del auenfurero que se encuentra en paradero ôsconocido o vaya usted a saber dónde.

Lia Jefa de Saluamento Terrestre. Socorro Liópez, se teme to peor ya que "no hay ni una sombrifa, ni una mísera fuente hasfa el Qarque Elcosa y ron la caló que está hariendo, el jamaruco no hay quipn se lo quife...". [ía Guardia Civil directamente ha firado la foalla (o más bien la ha exfendido sobre el céspeò de una piscina comunifaria $y$ se ha tendido en ella) y lo dan por muerto o desinfegrado pn su defecto. "G quién se le ocurre, si uas a hacer una locura así hajlo en invierno, con la fresquifa", han declarado tras darse un bañifo de reconocimiento.

Amigos y familiares del desaparecido insisten en llamar a Delacuadra Salcedo o al infrépido Calleja, para iniciar una nueva búsqueda por el Gliarafe. Seqún palabras de la misma abuela de Cristobal, Consolación Diefo, "insistía en que era más rápiòo llegar al Qarque Elcosa viajando hacia el opste y rodear la curuafura del planefa", sipndo este herho desrarfado por las auforidades que, en vo3 del delegado del gobierno en Sevilla, Enfonio Sanz, insisten en que "Lia Cierra es plana de foda la vida o al menos, àesde que gobiernan los españoles de bien".

los servicios más básicos, junto a un generalizado sentimiento de aislamiento, contribuyeron a generar una fuerte identidad propia entre la vecindad que propició que la población se juntase y se organizase para hacer oír su voz. ${ }^{11}$ Lo que es ahora el barrio, con su multiplicidad de funciones y servicios y con su gran potencial en cuanto a la calidad ambiental de sus espacios libres, es, sin duda alguna, resultado de un proceso de progresivas mejoras fruto de una intensa movilización vecinal a lo largo de todos estos años. Todos estos resultados y logros vecinales, más allá de quedar vivos en la memoria de las primeras generaciones de habitantes del barrio, tienen en muchos casos su propia huella física en Alcosa, convirtiéndose en elementos identitarios de gran valor (sobre todo en lo que se refiere a la mejora de los estándares de equipamientos y niveles dotacionales), como se verá más detenidamente en el próximo apartado (Figura 7).

El barrio se fue formando paulatinamente hasta principios de este siglo. Se pueden identificar tres fases principales en su construcción (Figura 8), cada una de las cuales se diferencia muy bien de las otras en cuanto a morfología urbana, tal y como se detallará a continuación.
Figura 6: Texto e imagen extraídos de la web de Sevillatoday. Autor: Antonio Sanz (https://sevillatoday.es/desaparecido-un-aventurero-que-buscaba-una-nueva-ruta-al-parque-alcosa//.
11 "Desde el primer momento tuvimos que luchar para conseguir cualquier cosa": Se trata de una expresión pronunciada muchas veces por vecinas y vecinos y escuchada durante el trabajo de campo. 


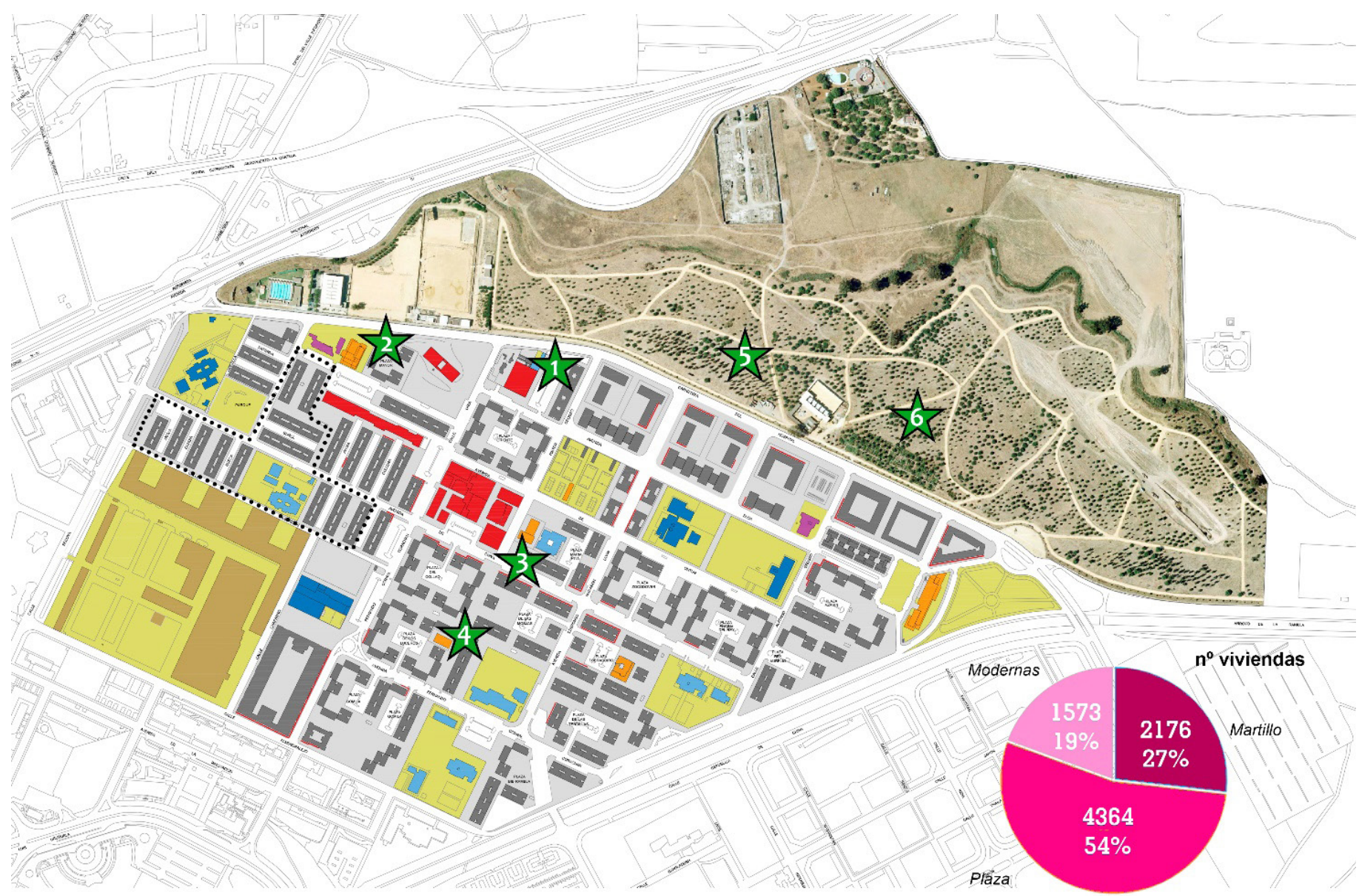

\begin{tabular}{|l|l}
\hline & Viario prevalencia peatonal \\
& Residenciales \\
& Comerciales y terciarios \\
& Equipamientos y servicios \\
& Educación infantil y Primaria \\
& Educación Secundaria o Superior \\
\hline & Núcleo industrial de la Algodonera \\
\hline & Parcelas equipamientos y terciario \\
\hline \\
\hline$\ldots . . . . . . .5$ & Núcleo histórico" del barrio
\end{tabular}

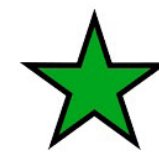

Principales logros vecinales

1/ Plaza de abastos (actualmente sin uso)

2/ Centro de salud

3/ Centro cívico + Biblioteca

4/ Centro de Educación de Personas Adultas

5/ Parque del Tamarguillo

6/ Huertos urbanos

Figura 7: Morfología urbana del barrio y principales logros de las luchas vecinales. Autor: elaboración propia.

12 La configuración física de esta parte del barrio (y con tipologías edificatorias similares) encuentra su antecedente en el barrio homónimo situado en la localidad de Alfafar, municipio al sur del área metropolitana de Valencia y construido por el mismo Alfonso Corral entre 1966 y 1983.

13 En realidad, con la expresión "martillo" los vecinos se refieren a las dos unidades de cabecera que cierran los bloques lineales, para diferenciarlos de los módulos
La primera fase del polígono, que como ya hemos dicho se inicia en 1969 y se inaugura en 1971, se sitúa al norte de la Algodonera, y constituye lo que muchas vecinas y vecinos definen "centro histórico" del barrio. ${ }^{12}$ Todos los edificios mantienen una continuidad en cuanto al aspecto exterior, otorgando un carácter uniforme a la zona: los bloques, lineales, se generan por adición de un módulo en forma de $\mathrm{H}$, que consta (exceptuando los de los extremos) de un núcleo de comunicación vertical (sin ascensor) y cuatro viviendas similares por planta. Este tipo de agrupación permite la generación de patios interiores entre escalera y escalera, que se van alternando con las calles. En el barrio son conocidos como los Martillos. ${ }^{13}$

Durante los años siguientes (en la década de los setenta y hasta los ochenta) empieza a aparecer un nuevo tipo de agrupación, más compleja, caracterizada por la disposición de bloques de diferente altura y configuración en torno a un espacio central (Figura 9). El gran espa- 


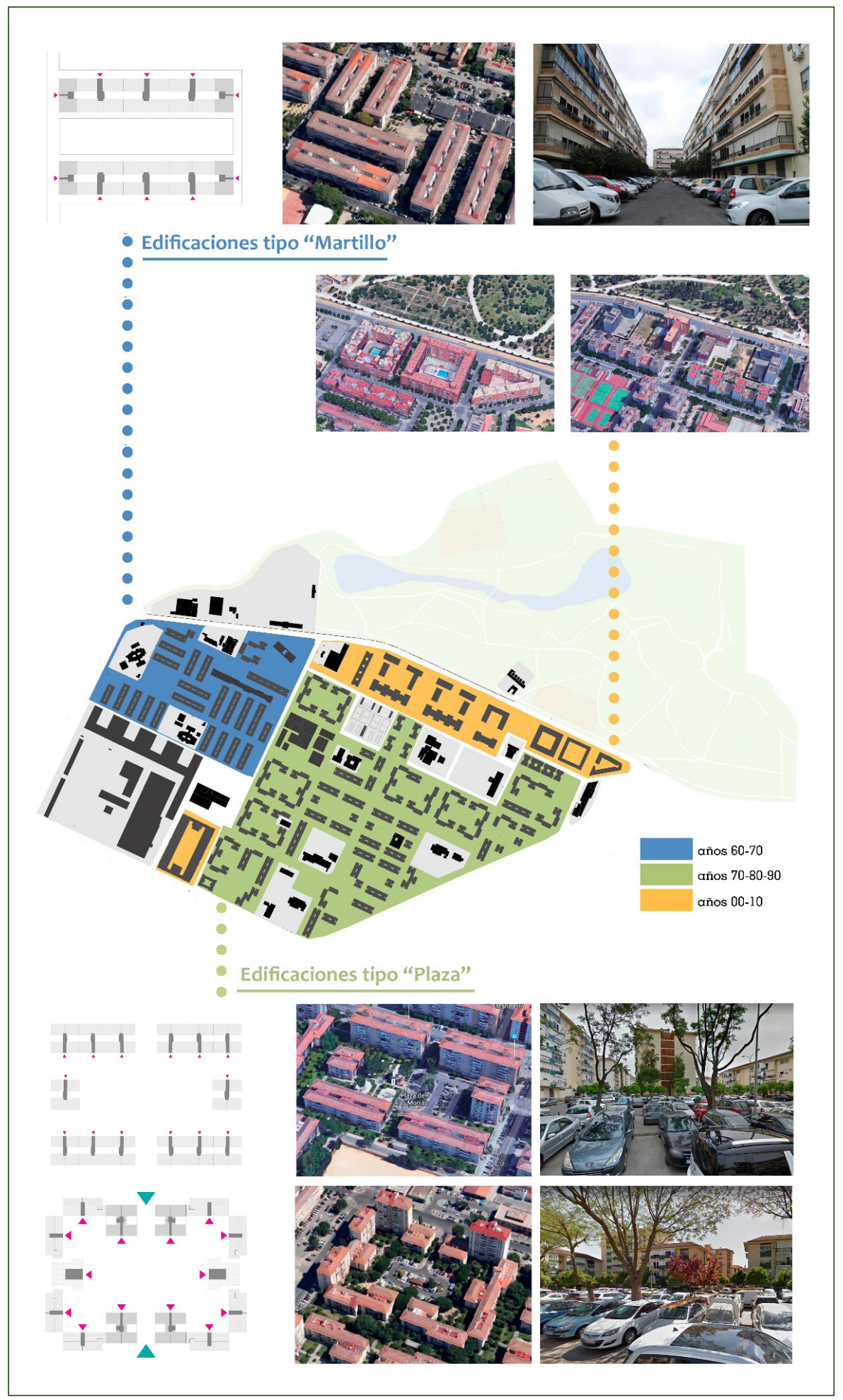

cio interior entre estos bloques estaba destinado a jardines, cada uno dotado de su pozo para el riego. Actualmente estas plazas (como las denominan los propios habitantes) se han convertido en grandes bolsas de aparcamiento, afectando de esta forma a la calidad del paisaje urbano, pero su existencia tiene un significado especial desde el punto de vista social: desde sus orígenes ha facilitado la integración de las vecinas y vecinos, tratándose de un espacio verde y recogido donde se podían establecer relaciones sociales de diferente tipo (PALC04), desde las más débiles (como charlar sentados en un banco, disfrutando del aire libre o vigilando a los niños y niñas mientras juegan) hasta las más fuertes (como la organización de los vecinos y vecinas en Intercomunida-
Figura 8: Evolución constructiva del barrio. Autor: elaboración propia lfotos extraídas de GoogleMaps). centrales, mientras que para referirse a toda la zona en su conjunto utilizan la expresión más genérica "bloques" (o "bloques antiguos"). De todos modos, para no generar confusión en el lenguaje, de aquí en adelante con el término martillo se hará referencia al bloque lineal en su conjunto, para diferenciarlo de las plazas y de los bloques de edificios más recientes, pertenecientes respectivamente a la segunda y tercera fases. 


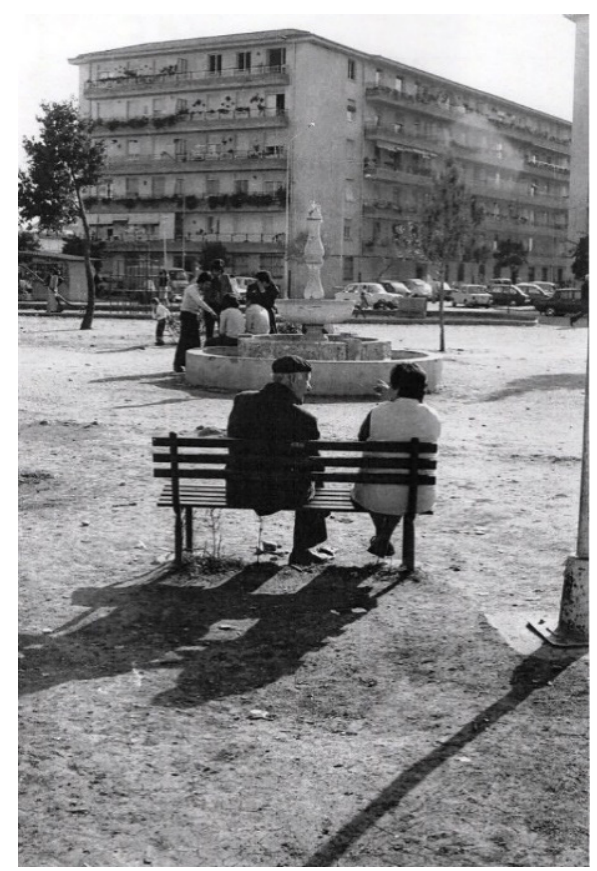

Figura 9: Plaza de Juan García Reyes (1975). Fuente: Hemeroteca ABC Sevilla. des, para facilitar el cuidado de las plazas de forma conjunta). Esto demuestra la estrecha relación existente entre URBS y CIVITAS, es decir, cómo la configuración espacial de nuestros barrios y ciudades puede favorecer o, al contrario, frenar el desarrollo de las relaciones sociales de quienes los habitan.

La última etapa supone la colmatación de unos cuantos solares vacíos situados en la franja norte del barrio, colindante con el parque Tamarguillo. En ella se pueden identificar dos fases (Figura 7): en la primera, a comienzos de la década pasada, se adopta la tipología del bloque con base cuadrada y patio interior; en la segunda se construyen los edificios comprendidos entre las calles Pintor Alfonso Grosso y Emilia Barral como ejecución del Área de Planeamiento Incorporado (API-DE-06 del PGOU 2006), con la cual se preveía el uso de bloques abiertos al igual que en numerosas formas de crecimiento urbano de la zona este de Sevilla.

\section{Las tres grandes etapas de la historia del barrio y sus principales hitos reivindicativos}

Sobre la base de cuanto analizado tanto en las entrevistas en profundidad como en la increíble cantidad de documentación a disposición, se puede afirmar que Parque Alcosa es un barrio caracterizado por una larga e intensa trayectoria de movilizaciones vecinales cuyo principal objetivo ha sido el superar las dificultades creadas por su condición periférica y aislada. Y como se adelantaba anteriormente, todos estos resultados y logros vecinales, más allá de quedar vivos en la memoria de las generaciones más antiguas, tienen en muchos casos su propia huella física en el barrio convirtiéndose en elementos identitarios de gran valor. Su largo y conflictivo proceso de urbanización encuentra su motor real en el marcado carácter reivindicativo de sus habitantes. ${ }^{14}$

La historia de Alcosa se podría dividir en tres etapas, que se desarrollan a continuación.

\section{Etapa 1. Las primeras movilizaciones vecinales y el liderazgo de la Asociación de Vecinos Antonio Machado}

La primera etapa se remonta a la década de los setenta. Consultando la prensa local de la época (entre 1971 y 1975) Parque Alcosa se presenta no como un barrio más, si no como un "nuevo estilo de vida". Así es como se "vende" a la prensa: un núcleo urbano autónomo, rodeado de "Parques Infantiles, Centros Comerciales, Escuelas, Zonas Ajardinadas, Iglesias, Centros de aparcamientos y diversión " (Texto de la Invitación oficial a la inauguración del barrio aparecida en el ABC Sevilla el 10 de julio de 1971, p. 30). Y fueron varias las estrategias promocionales anunciadas en la prensa para convencer a comprar un piso en un lugar tan a desmano (Figura 10):

-Según los proyectos que vieron los primeros vecinos que compraron las viviendas, vieron una maqueta que era una maravilla de barrio, porque tenía centro de salud, plaza de abastos, colegios suficientes repartidos, muy amplio (.) La gente cuando vio aquellos pisos que tenían ya 90 metros - cosa que en Sevilla no sucedía en la vivienda social nunca, pues (.) nunca hubo vivienda social <sonríe> de más de 50 o 60 metros, que es lo que había hecho la vivienda pública de Franco, no?-, entonces pues cla- 
ro, aquello (.) - Los primeros vecinos llegan maravillados por lo que creían que iban a tener, pero eso nunca se hizo realidad. De hecho, los primeros vecinos $[\ldots]$ viven allí sin tener terminadas las carrete- las calles, sin agua potable corriente, sin transporte público (.) por supuesto sin servicios, ni colegios ni médicos ni nada. Y tuvieron que luchar por todo eso los primeros (PALC01).

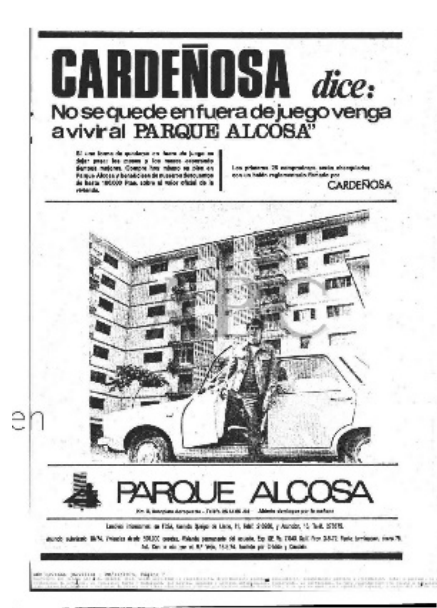

En el Parque Alcosa donde crecen las escuelas, los árboles, los centros comerciales, el deporte. vivimos el arecer de Sevilla. anding
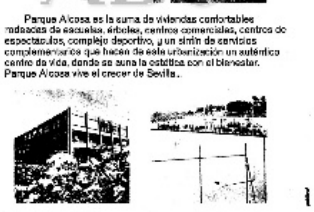

SRAROUE

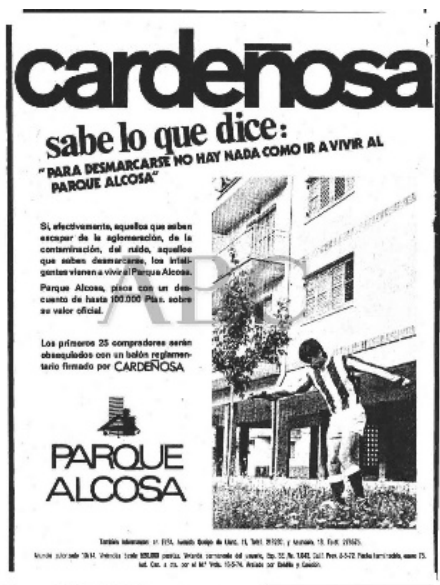

\section{Si 137 familias confian cada mes en Alcosa es porque...}

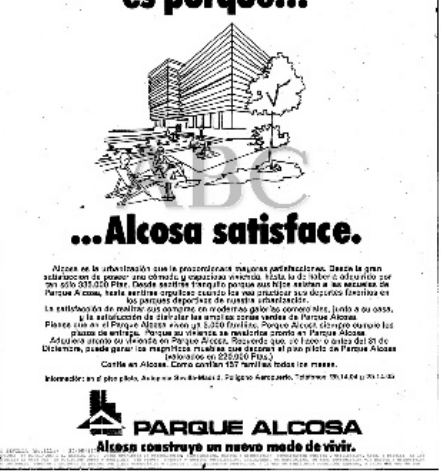

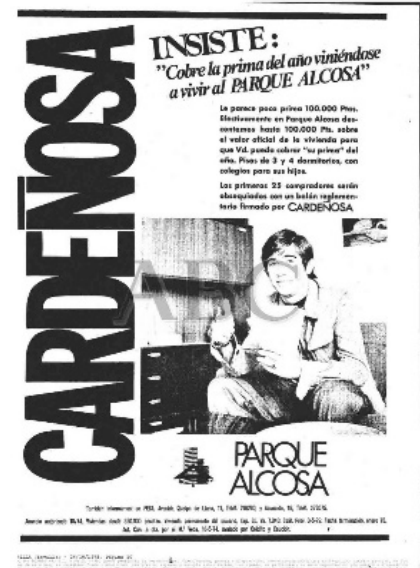

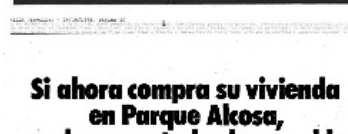
en Parque Alcosa,
puede ganar fodos los muebles
del piso piloto.

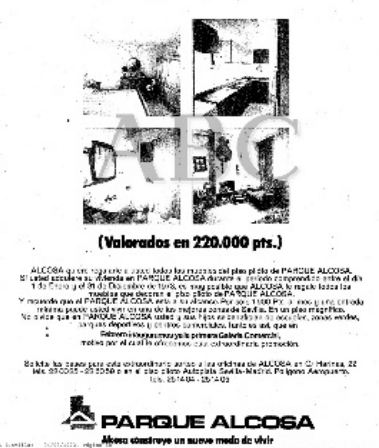

\section{CARDENTOSA}

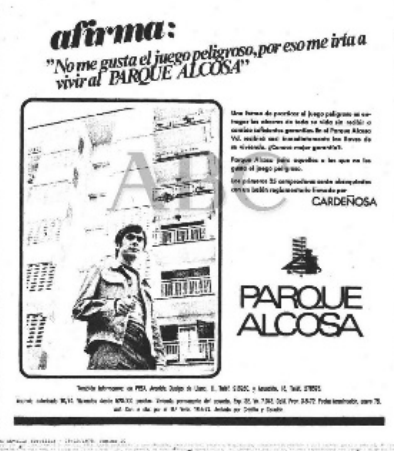

a la tercera va la vencida

500 니ROS DE GASOLINA GRATIS

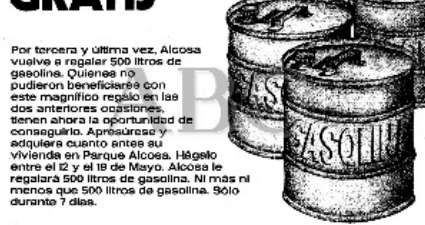

PARQUE ALCOSA

Alcosa construye un nuevo modo de vivir

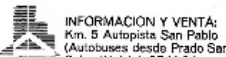

Entre los principales problemas y carencias destacaban:

- La falta de transporte público que conectase el barrio con la ciudad (los escasos autobuses de línea existentes, que se fueron añadiendo poco a poco, eran de una empresa privada, Damián Mllán S.A.).

- La ausencia de guarderías y colegios en una situación de incremento constante de la población infantil en el barrio (OTROS02; DOC01).

- La falta de Institutos de Educación Secundaria (una de las primeras acciones en este sentido fue llegar a acuerdos con la empresa privada de autobuses para llevar a los estudiantes a Institutos presentes en otros barrios) (PALC03).

- La ausencia de farmacias (OTROS02) y demás dotaciones de servicios sanitarios (PALC01; OTROS02).

- La contaminación existente, provocada por la actividad de la Cooperativa Algodonera Virgen de los Reyes (Cfr. ABC Sevilla, 04 de julio de 1978, p. 29).

En este contexto surge la Asociación de Vecinos "Antonio Machado" que poco a poco asume el liderazgo dentro del barrio, canalizando
Figura 10: Algunos de los anuncios publicados en prensa entre 1972 y 1975 Fuente: Hemeroteca ABC Sevilla. 
todo el movimiento ciudadano para la activación de los principales y sustanciales cambios en Alcosa, orientados sobre todo a la integración de servicios básicos ausentes: fue ella quien, por ejemplo, llegó a acuerdos con una empresa de autobuses, Damián Millán S.A., para llevar, a un precio asequible, a la población estudiante del barrio a los Institutos presentes en otros barrios cercanos.

\section{Etapa 2. Una nueva ola de movimientos reivindicativos y aparición de primeros conflictos para el liderazgo vecinal}

La segunda etapa se sitúa entre los años ochenta y noventa. En esta época, y sobre todo a partir de los años noventa, destaca sin duda el trabajo socio-educativo del Centro de Educación de Adultos con sus actividades de alfabetización, graduado escolar y animación sociocultural. Desde el comienzo de su actividad en el barrio este Centro (o mejor dicho sus docentes $)^{15}$ ha estado muy implicado en las diferentes reivindicaciones vecinales, hasta convertirse con el paso de los años en un verdadero elemento catalizador y dinamizador de muchas actividades e iniciativas en el barrio. En particular, a partir de los años 90 diferentes movimientos vecinales que orbitan alrededor del Centro de Personas Adultas empiezan a coordinarse en la Federación de Entidades de Alcosa (FEA) y bajo este nombre se impulsan diferentes movilizaciones, entre cuyos resultados más importantes se encuentran los siguientes:

1. La construcción de un Centro de Salud en la calle Ciudad de Paterna, que se aprueba en 1992 y se termina en 1996, pero que no se inaugurará hasta el $1997 .{ }^{16}$

2. La construcción del Centro Cívico en el año 2000, ubicado en la Avenida Ciudad de Chiva. ${ }^{17}$

3. La creación, dos años después, de una biblioteca pública (muy reivindicada por las personas jóvenes y las mujeres del Centro de Personas Adultas), que se abrirá en el mismo Centro Cívico y que forma actualmente parte de la red de bibliotecas municipales de Sevilla.

4. La demolición parcial en 2008 del centro comercial "Nueva Galería" en la plaza de los Luceros (muy protestado en aquel entonces por privar de aire, sol y luz a buena parte de los bloques que conforman la plaza) y su consiguiente conversión en el actual Centro de Educación de Personas Adultas. ${ }^{18}$

El último y mayor logro del activismo social en esta etapa fue el desarrollo del proyecto del Parque del Tamarguillo, cuya lucha empezó a finales de los noventa y que acabó consiguiendo en el 2011 la apertura del parque, financiado en su mayoría con fondos europeos. En este caso es otro el colectivo que lidera la movilización vecinal, la Asociación Movida Pro Parque Tamarguillo, que nace por impulso de las personas jóvenes que frecuentan el Centro de Personas Adultas; ese mismo colectivo, en la década pasada (cuando todavía el parque no se había inaugurado) puso en marcha un interesante proyecto de huertos de ocio autogestionados, pero cuya gestión actual ha pasado a las manos del Distrito.

bién a la de otros barrios.

18 Aunque, como ya se ha mencionado anteriormente, el Centro de Personas Adultas estaba activo en el barrio desde 1981 sin tener una sede propia. 
Etapa 3. La lucha para la rehabilitación de los bloques de viviendas y el protagonismo de la FEA y de la Asociación para la rehabilitación integral de Parque Alcosa

La última etapa (todavía abierta) se corresponde con los últimos 18 años, tiempo durante el cual la FEA asume un mayor grado de autonomía respecto al Centro de Personas Adultas y, junto a la Asociación para la Rehabilitación Integral (de más reciente formación), se activa para reivindicar un Plan Integral de rehabilitación de los bloques de viviendas. Esta última fase en la historia reivindicativa del barrio encuentra sus antecedentes en los primeros años de la década de los 90, cuando empiezan a aparecer las primeras grietas en diferentes bloques de edificios; este hecho provoca un gran alarmismo entre los vecinos y vecinas, que se movilizan primero en la búsqueda de apoyo técnico para diagnosticar la causa de dichas grietas, y luego para exigir a la Junta de Andalucía la declaración de Alcosa como Área de Rehabilitación Integral.
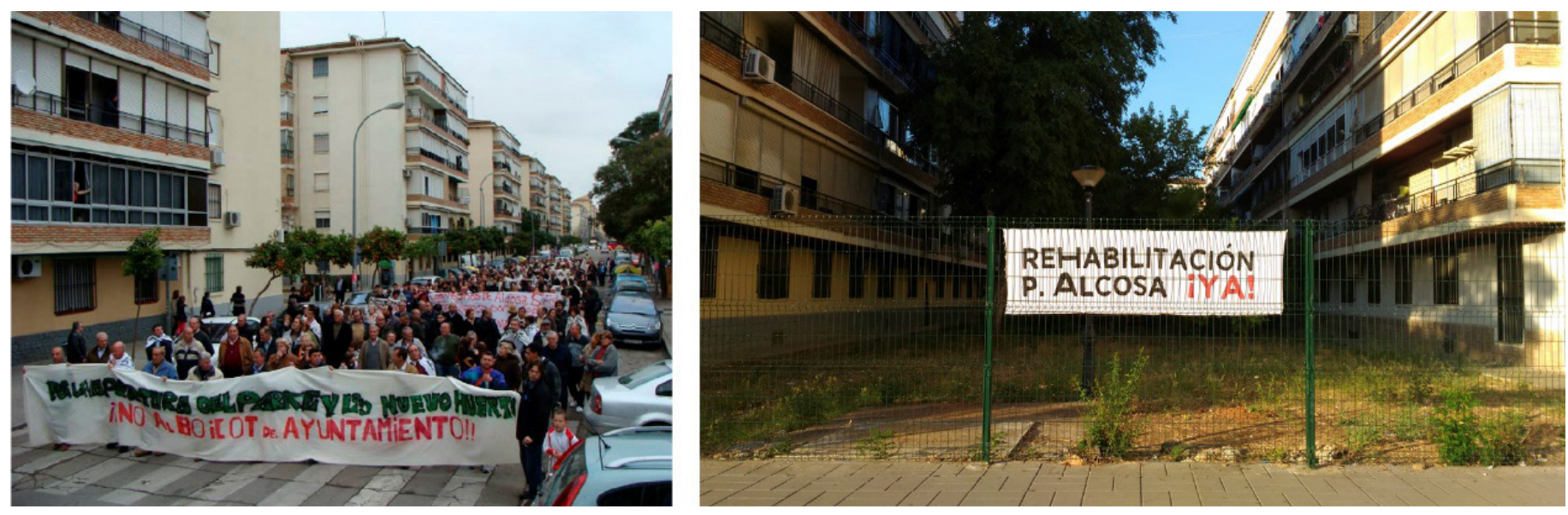

Como consecuencia de estas movilizaciones la Junta de Andalucía ha venido interviniendo en el barrio desde 2004 con una inversión de unos 10,5 millones de euros, ${ }^{19}$ aunque ya en 1995 el Gobierno andaluz había declarado Alcosa como Zona de Actuación Preferente.

Todos los diferentes programas de ayudas públicas e intervenciones para la rehabilitación que se sucedieron en el barrio ${ }^{20}$ se detuvieron en el año 2012 por la falta de fondos ocurrida con la crisis económica y financiera, a pesar de que persisten de forma generalizada las causas que motivaron la declaración de Área de Rehabilitación Integral. Así,

las movilizaciones por la Rehabilitación de Alcosa se han estrellado contra el muro del parón impuesto por las políticas ciegas de recortes, que empezaron por cancelar los programas de rehabilitación [...]. Los planes de rehabilitación del barrio se cancelaron y quedaron proyectos aprobados y con licencia en el cajón. Esto ha provocado desconfianza e incluso resentimiento por parte la población (Equipo Barrios en Transición, 2015, p. 140).

En 2016 desde la Junta de Andalucía se informó que tenía previsto declarar Alcosa como Área de Regeneración y Renovación Urbana $(\mathrm{ARRU})^{21}$ con el objetivo de volver a impulsar su rehabilitación. Las actuaciones iban a empezar en 2017 retomando los proyectos que se habían paralizado en 2012, pero de momento nada ha cambiado. Fren-
Figura 11: Reivindicaciones y luchas sociales en Alcosa. Fuente: autora (izda.) y Movida Pro Parque Tamarguillo (dcha.).

19 El total de las inversiones alcanza los 13,9 millones de euros, de los cuales la Junta ha aportado a través de AVRA el $60 \%$ (10,5 millones de euros), más los costes de gestión y las asistencias técnicas para la redacción de proyectos y dirección de obras, el Ayuntamiento de Sevilla el 20\% del coste de ejecución de las obras ( 1,4 millones) y las propias vecinas y vecinos el resto.

20 Con los cuales se han realizado intervenciones de cimentación, mejora de cubiertas e instalaciones generales y de accesibilidad.

21 Se trata de un Programa del Ministerio de Fomento que en Sevilla ya se ha aplicado en Polígono Sur. 
te a esta total inacción por parte de las diferentes administraciones, la FEA, junto con la Asociación de Rehabilitación Integral y con la Asociación Nosotras, celebró en abril de 2019 unas jornadas de consulta ciudadana en la calle sobre el problema de la rehabilitación.

\section{Las reivindicaciones en clave femenina: las carencias alrededor de las tareas de cuidado}

A lo largo de las etapas anteriores se mencionan algunas luchas que tienen la peculiaridad de haber estado lideradas por las mujeres del barrio; sin embargo, se trata de luchas en donde la mujer de alguna forma ha sido invisibilizada y cuyos logros han sido absorbidos en los listados de "éxitos" de los líderes barriales que se han ido turnando en el barrio (AAVV Antonio Machado y FEA), y en donde existe predominación masculina. De hecho, al mencionar estos logros durante las entrevistas ha quedado patente que los representantes de estos colectivos, todos hombres, desconocen realmente las dinámicas y detalles de estas luchas, las cuales son solamente un punto más en la lista de logros con la que defienden su imagen de cara al barrio. Por el contrario, las mujeres entrevistadas conocen perfectamente todas y cada una de las movilizaciones realizadas, independientemente de quién haya liderado realmente las acciones, precisamente por su presencia e involucración a la hora de apoyar las distintas causas.

La primera lucha femenina se remonta a la primera etapa: el boicot al supermercado y la lucha para obtener la plaza de abastos, entre 1974 y 1975. Actualmente solo queda una de aquellas mujeres que lideraron la lucha, la única testigo directa que conoce todos los detalles:

Cuando se abrió el supermercado llevábamos aquí dos años viviendo. Que lo primero que se abrió no fue el supermercao, lo primero que se abrió fue un bar y el Polvillo, y luego ya se abrió el supermercao. Pero así que aquí llevábamos ya (.) ya habíamos hecho hasta la Hermandad de la Virgen antes de que tuviéramos el supermercao!”. “[...] aún no teníamos puestos de verduras ni teníamos puestos de nada, venían unos hombres $<$ se refiere a los vendedores ambulantes $>$ a (.) al Parque, a la entrada del barrio. Venían unos hombres [...] a cada piso había un bajo, que también pusieron tiendecitas. Había uno que traía la carne del guiso que era bastante buena. Y así nos íbamos aviando (OTROS02).

Al tratarse de una venta no autorizada, las cosas no fueron fáciles ni para los ambulantes ni para las mujeres, que a menudo se veían obligadas a hacer colas en el supermercado para comprar productos de menor calidad. Incluso esta testigo habla de alguna especie de complot entre el propietario del supermercado y unos municipales para dificultar esta venta ambulante a las vecinas del barrio. Hasta que una tres o cuatro vecinas, indignadas por la situación, organizaron un boicot al supermercado:

Nos pusimos en la puerta del super diciendo que no comprara nadie, [...]. En ese momento éramos cuatro o cinco. [...] Entonces les dijimos $<$ se refiere aquí a otras mujeres que estaban comprando en el supermercado> que no (.) que no comprara, que no comprara que no se iba a llevar la mercancía. 'Hombre, cómo que no?' Digo: 'Que no te la vas a llevar!'. [...] 'No la pagues que no te la vas a llevar'. [...] La pagó, cogimos la mercan- 
cía, la tiramos al suelo y no se la llevó. Entonces se cerró el supermercado en ese momento y dijeron que por la tarde se abría. Pero por la tarde estábamos nosotras ya en la puerta para que no se abriera. Estaba nada más que abierto El Polvillo que había aquí y El Polvillo aquel, pero para el pan y la leche para los niños nada más. Lo demás no se compraba más en el barrio. [...] < golpea ligeramente la mesa con la mano> Llegó la noche, nos fuimos para arriba, pero a esto llamó alguien y dice: 'Vamos a ver, que en el super se van a llevar las cosas (.) Dice que se van a llevar las cosas para las monjas, [...]. Nos levantamos y nos fuimos todas, ya muchas - ya éramos muchas-, nos fuimos a la puerta del supermercado, y allí pasamos la noche para que no se llevaran las cosas (OTROS02).

Se tiró mucha comida y el supermercado quedó cerrado varios días.

Luego nos pasábamos las noches donde estaba la oficina de la promotora, para que la gente no comprara pisos. Porque no nos dejaban poner la plaza $<$ se refiere a la plaza de abastos $>$. Así nos llevamos más de 15 días, con los carteles puestos en los coches y en los balcones para que la gente no comprara pisos, porque no nos dejaban poner la plaza. Y todo coche que venía no lo dejábamos entrar en la oficina (OTROS02).

Al final consiguieron que se construyera una plaza de abastos, aunque se cerró a los pocos años. Al preguntar por qué duró tan poco tiempo, los y las diferentes informantes dieron esencialmente dos motivaciones:

- La plaza de abastos se situó en un lugar perimetral, lo que resultaba un poco incómodo para buena parte de la vecindad, es decir, para todas aquellas personas que vivían al otro lado del barrio, más allá de la Avenida de Chiva, tal y como comentan algunas de las primeras vecinas del barrio.

- A los pocos años de su apertura empezó la época de los grandes supermercados: llegaron las grandes superficies "con sus superofertas y se cargaron el mercado" (PALC01).

La segunda lucha eminentemente femenina sucedió ya en las etapas posteriores, cuando el liderazgo pasa a las manos de la FEA. En los años noventa, desde la FEA y el Centro de Personas Adultas había empezado una movilización para conseguir una sede propia y poder dejar de utilizar en horario de tarde las instalaciones del colegio Romero de la Quintana. Esta necesidad surgía de la sensación de estar viviendo constantemente un espacio que era solo prestado. Lo que se pedía en un principio era que el Centro de Personas Adultas tuviese su sede en una parte del edificio que se iba a construir para el Centro Cívico, cuya construcción "se puede decir que es un proyecto prácticamente del Centro de Personas Adultas, y de la asociación Nosotras"22 (PALC08), llegando incluso el alumnado del mismo centro a implicarse en el propio diseño del proyecto.

Efectivamente, era bastante complicado realizar la sede del Centro Cívico y la del Centro de Personas Adultas de una manera coordinada al ser cada uno de estos centros competencia de dos administraciones diferentes (el primero del Ayuntamiento y el segundo de la Junta de Andalucía). ${ }^{23}$ Pero no fue lo único que no obtuvieron: tampoco había dotación para la biblioteca, y en el lugar que hoy ocupa la biblioteca había un espacio de usos múltiples.
22 Asociación de las mujeres que pertenecían al Centro de Personas Adultas y que sigue todavía activa dentro del barrio. Aunque oficialmente todavía no existía la asociación como tal, este grupo de mujeres estaba ya conformado y activo dentro del Centro.

23 Cfr. ABC Sevilla del 03/08/97, p. 58. 
En el caso de la biblioteca no solo se organizaron manifestaciones de protesta. Incluso se idea la "apertura anticipada" de la biblioteca por medio de la realización de unos carnets "para llamar la atención para la biblioteca" (PALC04):

N: Entonces ideamos (.) 'nosotros abrimos una biblioteca, no físicamente, pero vamos a hacer los carnets ya de la biblioteca'. Claro! Y F. tenía conocimientos, conocía a Pilar del Río, la mujer de (.) de José Saramago, y que vivía en Lanzarote, claro. Le mandaron una carta y les mandamos unos carnets de biblioteca, [...] y ellos tienen el 90 y el 91, de números (.) ficticios! [...] Todo el mundo teníamos carnets de la biblioteca, unos carnets verdes muy - que no nos sirven, pero, bueno, yo lo tengo de recuerdo. Y él nos escribió, nos mandó la foto firmada, y Pilar del Río también. T: Por eso se llama nuestra tertulia 'José Saramago'. N: Entonces, a partir de ahí, es cuando (.) se inaugura la biblioteca ya por fin, con una dotación escasísima y eso. Y nosotros creamos la tertulia 'José Saramago', [...]. Eso lo crea, lo creamos, la gente de (.) que pertenecíamos a la asociación de alumnos (PALC04) (Figura 12).

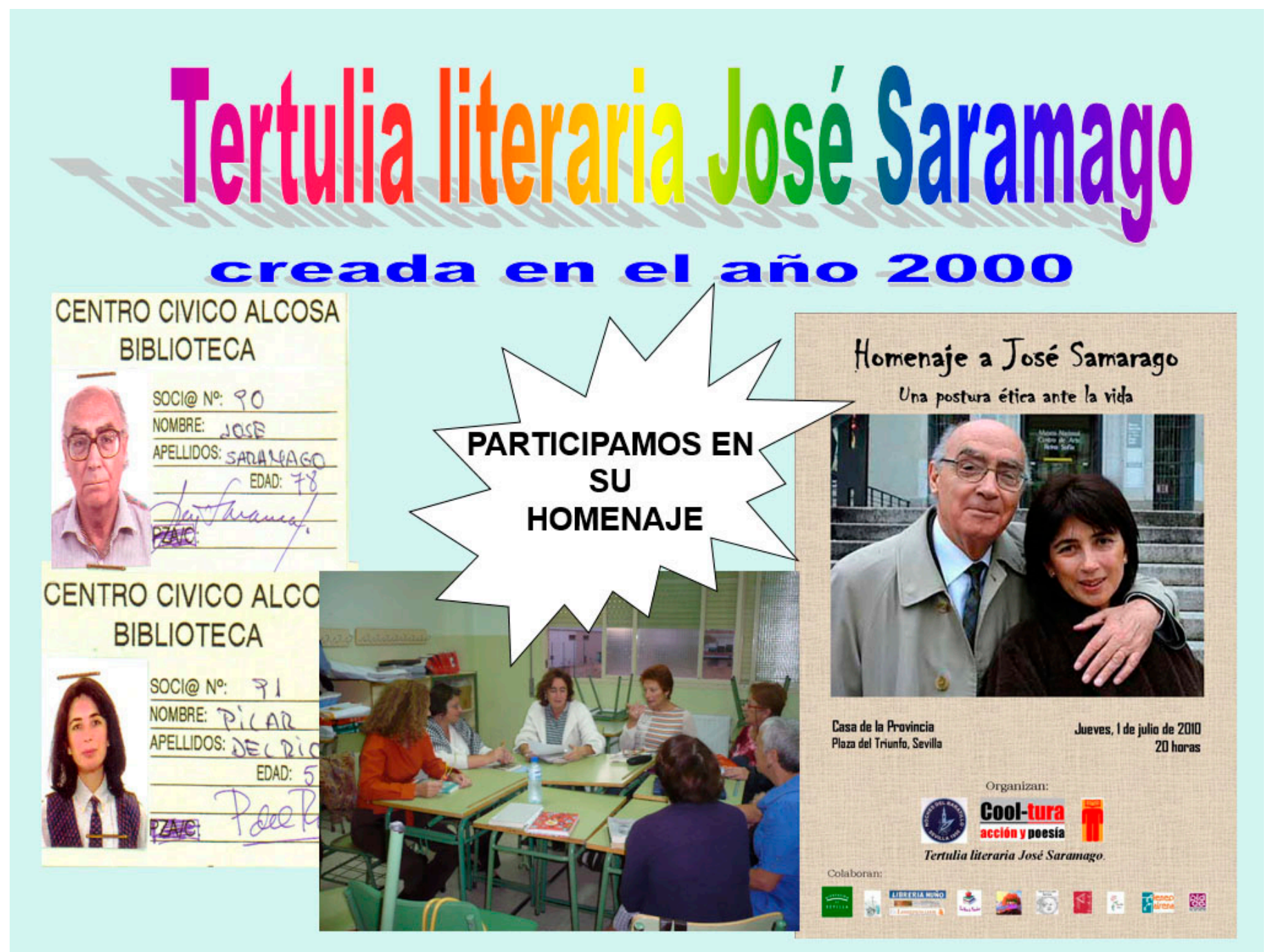

Figura 12: Imágenes de la tertulia y de los carnets 90 y 91 autografiados por José Saramago y Pilar del Río. Fuente: vecina del barrio.
Y cuando por fin se abrió la biblioteca en 2002, comentan las mismas vecinas que: 
En una semana o dos había mil y pico de inscritos en la biblio- con carnet ya oficial [...]. Decía la bibliotecaria que estaban desbordados, porque la gente acudía"; en poco tiempo "se ha quedado chiquitísima, muy chica, pero bueno. Sería una lucha que habría que montar otra vez, pero $[\ldots]<$ reímos $>$ (PALC04).

A lo largo de las entrevistas, lo que resulta más evidente es que el verdadero impulso de esta movilización en concreto viene principalmente de las mujeres, ${ }^{24}$ en cuanto se trata de un tema relacionado con la falta de equipamientos para el cuidado tanto de niños y niñas, como de adolescentes y jóvenes (sin existir realmente intereses político-partidistas, como sí sucede en otras luchas consideradas "importantes" del barrio, desde una perspectiva masculina). No obstante, en este caso no se trató de una lucha solamente de mujeres, sino que se implicó también la juventud del barrio, principal afectada por esta carencia.

Así, a raíz de cuanto escuchado durante las entrevistas y mirando con perspectiva a los diferentes movimientos reivindicativos producidos a lo largo del tiempo en el barrio, se puede resumir que, si bien las mujeres constituyeron a menudo una base potente e insustituible de lucha, fueron los hombres los que lideraron en su mayoría los diferentes procesos, invisibilizando de alguna manera (o de todos modos poniendo en segundo plano) aquellas luchas orientadas a conseguir mejoras del hábitat relativas a las "múltiples tareas necesarias para el mantenimiento de la vida cotidiana” (Valdivia, 2018, p. 70), tradicionalmente pertenecientes a la dimensión de la mujer y relacionadas con la alimentación y los cuidados.

\section{La CIVITAS transforma la URBS (y apela a la POLIS)}

Del estudio de la historia del barrio se puede ver cómo sus vecinas y vecinos han sabido hacer frente común a las dificultades generando ciudad ahí donde dominaban las carencias típicas de un NO-barrio. Se pone así de manifiesto la importancia del binomio URBS-CIVITAS: el fuerte carácter identitario, generado también por la condición de aislamiento (físico y administrativo) del resto de la ciudad, se ha ido reforzando a lo largo de los años precisamente por existir unas huellas físicas de las mejoras propiciadas y que han sido el resultado de los propios esfuerzos comunitarios en las luchas.

El efecto de esta implicación constante ha generado no solo aprendizajes mutuos y colectivos, sino sobre todo el refuerzo del vínculo afectivo de las vecinas y vecinos con su barrio: estas "sinergias afectivas" (González Morales, 2014), que incluyen la cotidianeidad y domesticidad de estos espacios vividos, han sido el motor de cambio esencial.

En particular, la actitud de los colectivos involucrados en las movilizaciones ha sido dúplice: por una parte, han demostrado una actitud proactiva orientada a organizarse para intervenir ellos mismos en el cuidado y mejora del barrio y de sus servicios; por otro lado, la mayoría de sus luchas han estado orientadas a reivindicar la intervención de las administraciones para solventar las numerosas carencias presentes, y cuya solución no puede depender solamente de ellos.

Con respecto a la primera actitud, esto es particularmente evidente en las intervenciones orientadas a mejorar la calidad del espacio público: efectivamente el amplio sistema de espacios libres ajardinados presenta una notable calidad ambiental y paisajística. Sin embargo, las
24 De hecho, mientras los informantes masculinos se limitan a citar esta lucha (o como mucho a esbozarla) son ellas, las mujeres, las que entran realmente en el tema aportando muchos detalles interesantes. 


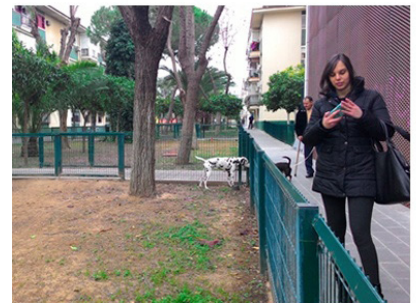

Sensación de espacio encerrado
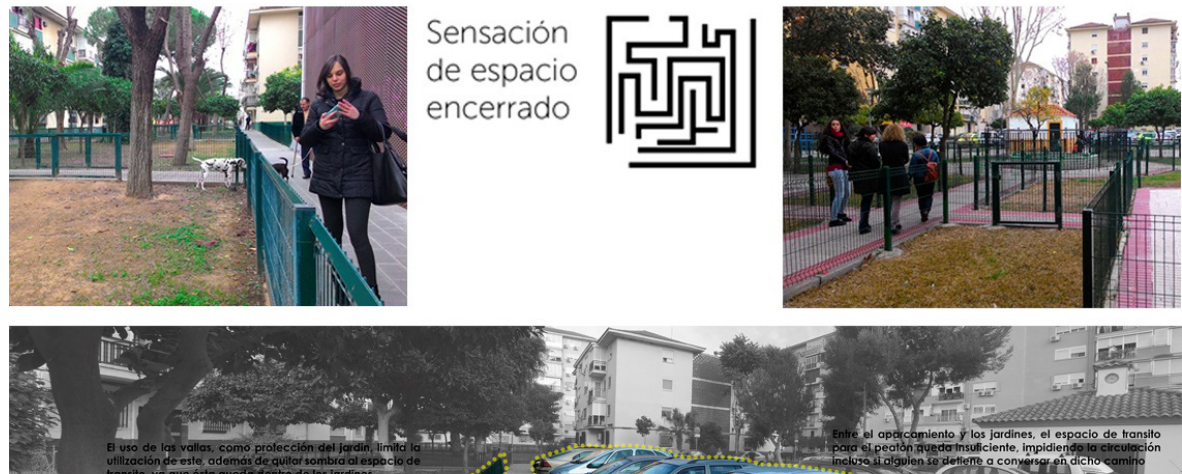

intervenciones de las últimas décadas por parte de las diferentes intercomunidades se han orientado a vallar estos espacios ajardinados, para convertirlos en espacios cerrados y muy regulados para garantizar la tranquilidad y un más fácil mantenimiento del verde: ${ }^{25}$ el efecto ha sido la generación de espacios laberínticos en los cuales el vallado toma protagonismo y las dimensiones de los recorridos peatonales se ven reducidos al mínimo; si a eso se le suma el hecho de que las plazas se han convertido en grandes bolsas de aparcamiento y la carencia de mobiliario urbano, hace que los que en un principio podrían ser potentes espacios de relación se vean reducidos a meros lugares de paso (de Manuel Jerez, González Arriero y Donadei, 2016) (Figura 13).

En ese sentido parece acertado buscar una posible relación entre los efectos de estas últimas intervenciones en el EP y la falta de participación detectada en los últimos años por buena parte de los vecinos $y$ vecinas que se han entrevistado (CIVITAS > URBS > CIVITAS)

En lo que se refiere a las reivindicaciones que piden la intervención de las administraciones, sobre todo con respecto a las últimas luchas orientadas a conseguir que la Junta de Andalucía asuma el cargo de la rehabilitación integral de todo

Figura 13: La situación actual de muchas de las áreas peatonales del barrio. Fuente: autora (fotos de arriba); estudiantes de la Escuela de Arquitectura de la US lideograma de arriba e imagen de abajo).
25 Entre los diferentes problemas mencionados por los informantes aparecen el ruido de los niños que juegan a la pelota o el generado por las "botellonas" que los jóvenes realizan en los bancos existentes; en algunos casos se menciona también el problema de jóvenes que iban a pincharse al cobijo de los árboles. En definitiva, es el resultado de conflictos espaciales no resueltos de tipo intergeneracional. A esto se suma el problema de privacidad relacionado con el hecho de que la mayoría de los bajos están destinados a vivienda: así, vivir en un bajo genera a menudo la percepción de que la gente mira dentro de tu casa y la consiguiente sensación de vivir casi "en la calle". el barrio, hay que tener en cuenta que la situación de escasez de recursos públicos en la que nos movemos actualmente hace difícil continuar con las políticas paternalistas llevadas a cabo hasta ahora. En este sentido, resulta necesario fomentar un cambio de enfoque orientado a buscar soluciones más asequibles para la rehabilitación de los bloques (respecto a las que se han llevado a cabo hasta el día de hoy). Las nuevas propuestas deberían tener en cuenta dos posibles escenarios futuros:

- Si la administración vuelve a involucrarse en la rehabilitación del barrio, deberán comportar un gasto que sea asumible para abarcar todos los bloques de viviendas afectados.

- Si, por cualquier razón, la administración no se involucra, deberán integrar y proponer diferentes fórmulas para la auto-organización para que las vecinas y vecinos puedan conseguir por si solos la rehabilitación de las viviendas (por ejemplo, mediante la creación de cooperativas para la formación de desempleados y consiguiente generación de puestos de trabajo, etc.).

Por otro lado, sería deseable que desde la POLIS se activasen políticas orientadas a suportar y fomentar estas formas de auto-organización ciudadana, para facilitar procesos de abajo-arriba orientados a una mejora eficaz del propio Hábitat social.

\section{La cooperación técnico-ciudadana como nuevo eje de acción abajo-arriba}

En conclusión, podemos afirmar que el barrio de Parque Alcosa reúne los atributos de "lugar" (Augé, 1994) en cuanto es un espacio identita- 
rio, relacional e histórico; se trata de un barrio vivo y con memoria, que aún conserva, especialmente a través de sus primeros habitantes, un patrimonio sociocultural en forma de experiencias organizativas, saberes y formas de vida populares que puede jugar un papel importante en la construcción de formas renovadas de autogestión y cogestión urbana para la sostenibilidad. Se trata en buena medida de un barrio que puede ser considerado de Producción Social, presentando características que lo sitúan como ámbito de oportunidad para asentar políticas y prácticas ciudadanas de transición hacia la sostenibilidad.

No obstante, es necesario hacer hincapié en la necesidad de una cooperación técnico-ciudadana, que canalice las acciones y las actitudes proactivas de la ciudadanía (o las fomente, aún más en el caso de barrios con escasa identidad y poca involucración comunitaria) para dar respuestas adecuadas a las necesidades vecinales. Esta cooperación, si está bien planteada, permite pasar de una cultura reivindicativa a otra basada en la integración de la ciudadanía en las decisiones sobre el hábitat y en la co-responsabilidad y co-decisión en la participación (García Roca, 2004).

En ese sentido, el personal técnico experto ${ }^{26}$ es él que puede poner al servicio de la comunidad sus conocimientos y las herramientas útiles para definir, de forma participada, los satisfactores complejos más adecuados para dar respuestas a las necesidades explícitas e implícitas diagnosticadas. ${ }^{27}$ Por otro lado, una actuación únicamente desde la componente técnica no es suficiente en cuanto resulta necesaria la implicación de la ciudadanía en la configuración de sus escenarios cotidianos.

En ese sentido, sería necesario construir el cambio desde una base técnico-ciudadana en la que confluirían los saberes técnicos y vivenciales (Donadei, 2019b) y cuya cooperación se basará en la aplicación de metodologías participativas de diseño urbano y planificación (Figura 13). Es importante aclarar que los equipos técnicos tienen que estar familiarizados con conceptos y herramientas de la Producción y Gestión Social del Hábitat, promoviendo el diálogo y la negociación entre perspectivas diferentes, y a menudo divergentes o contrapuestas dentro del ámbito de actuación, para pasar de reclamaciones vecinales a estrategias propositivas en las cuales se intente eventualmente involucrar, con el paso del tiempo, al vértice político-administrativo. A ello habría que

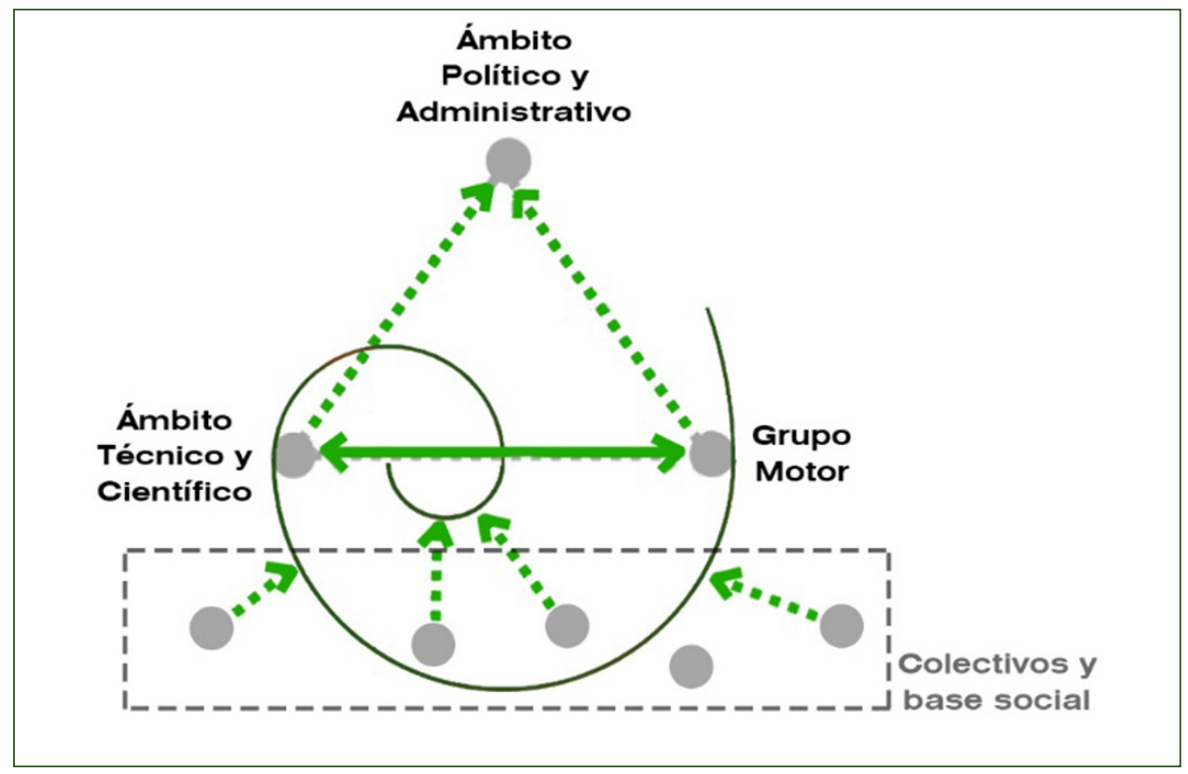

Figura 14: La activación de procesos de transformación del hábitat abajo-arriba desde la base técnico-ciudadana. Fuente: autora a partir de de Manuel Jerez (2010) y Red Cimas (2015).
26 Cuando se hace referencia a la esfera técnica nos referimos a equipos de carácter interdisciplinar, en los cuales confluyen disciplinas procedentes de la arquitectura, el urbanismo, la geografía, la economía, la sociología, la educación, etc.

27 Se hace referencia aquí a las categorías conceptuales de necesidades y satisfactores de necesidades introducidas por Max Neef et al. (1998). 
añadir la necesidad improrrogable de trabajar hacia un cambio del paradigma urbano en donde "los cuidados y la sostenibilidad de la vida" —en definitiva, todas las personas- "estén en el centro de las decisiones urbanas" (Valdivia, 2018, p. 81).

Así, resulta imprescindible superar los actuales planteamientos y modelos paternalistas que ven en la ciudadanía meros consumidores con derecho a reclamación (de Manuel Jerez et al., 2012) para abrir el camino hacia nuevas políticas públicas que fomenten la cogestión o incluso la auto-organización, superando al mismo tiempo el actual paradigma urbanístico marcado por el modelo capitalista y que basa la configuración de las ciudades en una dicotomía artificial de lo público/privado y de lo masculino/femenino (Murillo, 1996; Muxí, 2009; Valdivia, 2018).

En realidad, en el contexto del barrio objeto de este caso de estudio se trata de una tarea extremadamente compleja dado que un modelo de este tipo no podrá echar raíces sin un trabajo a priori que active un cambio en la mentalidad de sus habitantes, puesto que desde sus testimonios sobresale con fuerza el hecho de que son ellos mismos los primeros en considerarse simples usuarios con derecho a reclamación. 


\section{Referencias bibliográficas}

Asuero Sánchez, Nati (2008). Jóvenes. En Calvo Azpeitia, María Luisa (Ed.), Cruce de Miradas (pp. 130137). Sevilla: Tertulia José Saramago y Centro de Educación de personas adultas Manolo Collado.

Bonora, Paola (2006a). Percorsi della socialità e della partecipazione negli spazi deterritorializzati dell 'urbano. Inchiesta, 152, 3-5.

Bonora, Paola (2006b). Sistemi local territoriali, transcalarità e nuove regole della democracia dal basso. En Marson, Anna (Ed.), Il progetto di territorio nella città metropolitana (pp. 113-120). Firenze: Alinea.

Capel, Horacio (2003). A modo de introducción: los problemas de las ciudades, URBS, CIVITAS y POLIS. Mediterráneo Económico, 3, 9-22.

Capel, Horacio (2011). El urbanismo, la política y la economía (y viceversa). Una perspectiva comparada. Hábitat y Sociedad, 2, 155-178. DOI: https://doi. org/10.12795/HabitatySociedad.2011.i2.08.

Comisión de Turismo (1967). Segundo Plan de Desarrollo Económico y Social (1961-1971). Madrid: Presidencia del Gobierno.

Contrera Becerra, Javier (2019). Movimiento vecinal y Movimiento andalucista: construcción de la ciudadanía y aprendizaje democrático en Andalucía (1963-1987) [Tesis doctoral]. Granada: Universidad de Granada.

Corona Pariente, Francisco (2002). Historia de un barrio de Sevilla: Alcosa Eo Historia de una plaza de Sevilla: pza del Padre Castro. Sevilla: Impresiones y Creaciones Giralda.

De Manuel Jerez, Esteban (2006). Participar para recuperar la Polis. En de Manuel Jerez, Esteban: Educación de adultos y Participación (pp. 89-102). Palomares del Río: Unilco.

De Manuel Jerez, Esteban (2010). Construyendo triángulos para la gestión social del hábitat. Hábitat y Sociedad, 1, 13-37. DOI: 10.12795/HabitatySociedad.2010.i1.02.

De Manuel Jerez, Esteban y Donadei, Marta (2018). La extensión universitaria como dinamizadora de la función social compleja de la universidad. Estoa, 7(14), 115-127. DOI: 10.18537/est.v007.n014.a09.

De Manuel Jerez, Esteban, González Arriero, Conso y Donadei, Marta (2016). Las redes de Movilidad Urbana Sostenible y la reactivación del Espacio Público: Alcosa. Hábitat y Sociedad, 9, 97-131. DOI: http://dx.doi.org/10.12795/HabitatySociedad.2016.i9.06.

De Manuel Jerez, Esteban y López Medina, José María (2017). Dinamizar la regeneración urbana desde la escala barrial: aprendizajes y transferencias del proyecto Barrios en transición. Ciudades, 20, 21-44. DOI: 10.24197/ciudades.20.2017.1-24.
Deslauriers, Jean Pierre (2004). Investigación cualitativa. Guía práctica. Pereira: Papiro.

Díaz Hernández, Ramón y Parreño Castellano, Juan Manuel (2006). La política económica, la construcción de vivienda y la producción de la ciudad en España (1939-75). Scripta Nova, X(218), 48. Recuperado el 30 de enero de 2021, de: http://www.ub.edu/ geocrit/sn/sn-218-48.htm.

Donadei, Marta (2019a). Aportaciones para la definición de una metodología para la investigación cualitativa en el urbanismo. Ciur, 125, 1-77. DOI: 10.20868/ciur.2019.125.4313.

Donadei, Marta (2019b). El papel de la participación en la transición socio-ecológica de la ciudad. Retos, 9(17), 55-70. DOI: 10.17163/ret.n17.2019.04.

Erlandson, David et al. (1993). Doing naturalistic Inquiry: a guide to methods. London: SAGE.

Equipo Barrios en Transición (2015). Barrios en Transición. Diagnóstico y estrategias para la Rehabilitación Urbana Sostenible de Parque Alcosa: Avance de Proyecto. Documento para la concertación y participación. Sevilla: Consejería de Fomento y Vivienda-Junta de Andalucía.

García Roca, Joaquín (2004). Políticas y programas de participación social. Madrid: Síntesis.

González Morales, Ángel L. (2014). Sinergias afectivas. El paisaje como origen de un proceso de intermediación ecológico-cultural. Urbano, 30, 104-114.

González Ordovás, María José (2013). El derecho a la vivienda. Reflexiones en un contexto socioeconómico complejo. Madrid: Dykinson-Universidad de Zaragoza.

Lefebvre, Henri (1968). El derecho a la ciudad. Barcelona: Península.

Ley 84/1961, de 23 de diciembre, sobre Plan Nacional de la Vivienda para el periodo 1961-1976. BOE núm. 310, de 28 de diciembre de 1961, páginas 18215 a 18216. Recuperado el 30 de enero de 2021, de: https://www.boe.es/buscar/doc.php?id=BOEA-1961-23794.

Lucio-Villegas Ramos, Emilio Luis (1991). La Investigación Participativas en procesos educativos con adultos: el caso del "Parque" [Tesis doctoral]. Sevilla: US-Departamento de Teoría e Historia de la Educación y Pedagogía Social.

Max Neef, Manfred, Elizalde, Antonio y Hopenhayn, Martin (1994). Desarrollo a escala humana: conceptos, aplicaciones y algunas reflexiones. Barcelona-Montevideo: Icaria y Nordan.

Montañes Serrano, Manuel (2010). La entrevista. Madrid: Cuadernos CIMAS.

Morin, Edgar (2004). La epistemología de la complejidad. Gazeta de Antropología, 20(Artículo 2). 
Murillo de la Vega, Soledad (1996). El mito de la vida privada. De la entrega al tiempo propio. Madrid: Siglo xxi de España.

Muxí Martínez, Zaida (2009). Recomanacions per a un habitatge no jeràrquic ni androcèntric. Barcelona: Institut Català de les Dones / Generalitat de CatalunyaDepartament de Medi Ambient i Habitatge.

Naredo, José Manuel (2010). Raíces económicas del deterioro ecológico y social. Más allá de los dogmas. Madrid: Siglo XXI.

Patton, Michael (2002). Qualitative research and evaluation methods. London: SAGE.

Pelli, Victor Saúl (2007). Habitar, participar, pertenecer. Acceder a la vivienda: incluirse en la sociedad. Buenos Aires: Nobuko

Pelli, Victor Saúl (2010). La gestión de la producción social del hábitat. Hábitat y Sociedad, 1, 39-54. DOI: https://doi.org/10.12795/HabitatySociedad.2010. i1.03.

Pérez Barrasa, Teresa, Rodriguez Coma, Magdalena y Blanco Moreno, Ángela 2011. Política de gasto en vivienda. Papeles de trabajo del Instituto de Estudios Fiscales. Serie economía, 1, 7-50.

Red CIMAS (2015). Metodologías participativas. Sociopraxis para la creatividad social. Madrid: Dextra Editorial.

Sánchez-Rubio García, Belén (2009). Reflexiones sobre la evolución en la visión y conocimiento del diagnóstico y la intervención participativa a través del curso de Experto posteriormente Máster. Madrid: Cuadernos CIMAS.

Sassen, Saskia (2011). Open Source Urbanism. The new city reader: a newspaper of Public Space, 15. Recuperado el 3 de febrero de 2021 de: https:/ / www.domusweb.it/en/opinion/2011/06/29/open-sourceurbanism.html.

Troitiño Vinuesa, Miguel Ángel (1991). Centro histórico, intervención urbanística y análisis urbano. Anales de geografía de la Universidad Complutense, 11, 25-48.

Valdivia, Blanca (2018). Del urbanismo androcéntrico a la ciudad cuidadora. Hábitat Y Sociedad, 11, 6584. DOI: https://doi.org/10.12795/HabitatySociedad.2018.i11.05.

Valles, Miguel (1999). Técnicas cualitativas de la investigación social. Reflexión metodológica y práctica profesional. Madrid: Síntesis.

Verdaguer Viana-Cárdenas, Carlos (200a2). Ecologismo urbano y urbanismo ecológico: convergencia necesaria. El ecologista, 34, 16-18. Recuperado el 12 de noviembre de 2020, de: http:/ / oa.upm.es/5929/.

Verdaguer Viana-Cárdenas, Carlos (2002b). El paisaje construido: una perspectiva ecológica. En Bermejo García, Oscar y Laforet, Juan José (Eds), Ecología, una perspectiva actual (pp. 155-182). Telde: Real Sociedad Económica de Amigos del País de Gran Canaria.

Donadei, Marta (2021). Los movimientos vecinales en Parque Alcosa (Sevilla). Claves para avanzar de una cultura de resistencia hacia la construcción de alternativas para la mejora del hábitat. Hábitat y Sociedad, 13, 71-96.

<https://doi.org/10.12795/HabitatySociedad.2021.i14.05> 